\title{
Taguchi Optimisation of Cast Geometries for A356/Organic Particulate Aluminium Alloy Composites Using a Two-Phase Casting Process
}

\author{
Stephen Chidera Nwafor, Sunday Ayoola Oke*, Chris Abiodun Ayanladun \\ Department of Mechanical Engineering, University of Lagos, Lagos, Nigeria
}

\begin{abstract}
The A356 alloy is widely known to exhibit an extremely superior casting, machining, mechanical, and corrosion resistance properties. Despite these, it constitutes an environmental nuisance at its improper disposal for worn-out engine blocks. Also, organic reinforcements have the potentials to reduce the environmental impacts of composites. Consequently, there exits significant research potential to fuse A356 alloy with organic materials to obtain enhanced composite properties. In the area of aluminium matrix, as melting and solidifications of materials are done the accuracy of measurements is driven by the huge array of process parameters and the geometrical aspect of cast components is important. For these reasons, we attempt to solve the problem of optimising the geometry of casts in a complicated scenario with the use of the robust Taguchi's methods. To optimise the framework, the significant process parameters are identified and their effects studied in a route using Taguchi, Taguchi-Pareto and Taguchi$A B C$ methods. Parameters such as the volume of the cast, length, weight, density, height, width, breadth, weight loss and the total weight of organic materials infused into the melting process were studied for parametric changes, interactions and optimisation with $L_{27}$ orthogonal array. The analysis of variance for the A356 alloy cast revealed that the density parameter of cast 1 had the highest and major significant effect on the casting process with a variance of 333573, followed by weight parameter of casts 1 and 2, total weight of organic material parameters and weight loss with the variance values of 0.007, 0.005, 0.001 and 0.004, respectively. The variance of other parameters was insignificant to the A356 alloy cast.
\end{abstract}

Keywords: Casting, optimisation, developing country, A356, ANOVA

\section{Introduction}

Recently, there has been growing attention in the vision for environmental-oriented manufacturing and the concern that wastes should be converted into wealth [1-4]. In automobile engineering in developing countries, the general practice is to dispose of out-of-use engine blocks and parts and such practices often lead to environmental pollution due to the reactions of the metallic parts with soils in the long-run, and the contamination of soils with engine oil remnants from the engine blocks [5]. Engine block re-use can be made in a melting and solidification process for new product formation in a casting process, particularly in foundry systems wherewith the A356 alloy matrix may be complemented with reinforcements for enhanced corrosion, wear and mechanical properties [6-9]. This means that A356 alloy auto-parts, which are often disposed of as wastes have strong potentials to be transformed into new, exciting, useful and innovative engineering products such as the tyre wheel cover, among others, as the A356 alloy is infused with organic reinforcements. A number of current research papers discuss the probable advantages of

\footnotetext{
* Corresponding author. Tel.: +2348058179170

E-mail address: soke@unilag.edu.ng
}

Manuscript History:

Received 24 July, 2019, Revised 29 September, 2019, Accepted 29 September, 2019, Published 30 September, 2019

e-ISSN: 2289-7771

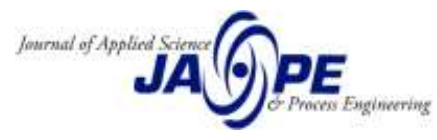


reinforcing A356 with organic materials (e.g. [10-13]), whereas other investigators have exhibited crucial concern about specific property enhancement for the A356 reinforced composites, including corrosion resistance [14], surface enhancement [15], microstructural and associated property enhancement through heat treatment [16-21]. The reported studies are nonetheless principal papers regarding metallic reinforced A356 alloy while very scanty papers were noted for organic reinforced A356 alloy, indicating a very restricted number of experimental research available in the literature on A356 alloy organic reinforced composites. As the relevant papers are crucial to this study they are briefly reported here.

Aigbodion and Ezema [10] directed attention to the nano-scale of palm kernel shells as reinforcements to A356 alloy in an analysis relating to microstructure and mechanical characterisation. A constant spread of the nano-scale particles of palm kernel in the A356 alloy was noted. A 4.26\% misalignment of the reinforcement and matrix at the interface was reported also. An exciting array of enhancements in the yield strength, impact energy, tensile, \% elongation and hardness were noticed to be $49.52 \%, 65.09 \%, 41.91 \%, 40.90 \%$, and $30.47 \%$, respectively, at $4 \mathrm{wt} \%$ of nano-scale palm kernel shell ash. The research ascertained that the built-up composite could be potentially employed in applications involving several tasks that require the joint actions of strength and toughness. Nwobi-Okoye et al. [13] established the requirement to optimise A356 alloy reinforced with cow horn particles using the modelling viewpoint while subjecting the age-hardening process factors to investigations. A particular interest was the ageing behaviour using the influence of artificial neural network modelling as well as the adaptive neuro-fuzzy influence scheme. The results indicated that ANN having coarse data to learn is largely competent and preferable to ANFIS to predict the outcome of the age-hardening experiment with the A356 alloy integrated with the cow horn particles. In a related study by reinforcement type, Ochieze et al. [12] studied the wear characterisation involving the use of cow horn particles as reinforcements in A356 alloy while the route taken was the spark plasma sintering process. Taguchi's unique method of optimisation was engaged to determine the most advantageous parametric values of the process. It was noted that an attractive and superior performance of the reinforced A356 alloy to the unreinforced alloy was noted in terms of wear resistance carried out in the dry condition. The experimental outcome revealed that by adding particulate cow horns in the A356 alloy, the wear resistance grew substantially.

A critical reflection of the organic reinforced A356 alloy literature suggests that abori wood has the potential of complementing matrices in composites for significant property enhancement. Particularly from the polymer composite literature stem multiple studies, suggesting the wood as result-oriented reinforcements in composites. Important as the genuine drive to eradicate aluminium may be, it is extremely difficult at present to find competing for polymer composites that rivals in terms of the outstanding properties that aluminium possesses. Granted that aluminium is not degradable and its disposal causes environmental threats, a promising strategy to achieve a reduction in the after-use disposal pollution of A356 is to combine organic reinforcement with it, serving the multiple functions of reducing environmental pollution, reducing cost, lessening the final products' weights and being available to source for in many communities of developing countries. This implies that it is a good and promising initiative to reinforce A356 with abori wood and other organic particulates. In this paper, we offer the findings of an optimisation study using newly developed Taguchi modified models, primarily Taguchi-Pareto and Taguchi-ABC, built-up recently by Ajibade et al. [22] and then compare the findings with the classical Taguchi method. The problem solved is the challenge of attaining accurate measurements to optimise the process parameters during the changes in one casting process to another. In this situation, the process controller is in a complicated scenario wherein a substantial number of process parameters are to be managed. The diverse parameters confronted with include volume of the cast, length, weight, density, height, width, breadth, weight loss and the total weight of organic materials infused into the melting and solidification processes evaluated for parametric changes, interactions and optimisation with $\mathrm{L}_{27}$ orthogonal array.

This paper is carried out of a larger study with a focus on the superior usage of A356 engine block wastes for new product development. Of course, the mere desire to attain superior new product

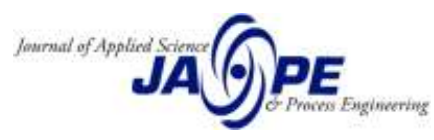


development from wastes is in itself insufficient to attain significant environmental pollution-free practices in developing countries. To attain the environmental pollution-free scenario concerning the disposal of out-of-use engine blocks from automobiles, it is essential to study in an in-depth manner the influencing parameters that offer challenges in obtaining accurate measurements during the casting of components, such as the automobile wheel cover having complex geometry. This will help us to exploit the advantages of out-of use A356 alloy, almost at free of cost, including superior casting properties associated with outstanding machining, mechanical and corrosion resistance. It is thereby important the accuracy of measurements that will often need a long-term journey together with constant attempts has begun in this paper by introducing the concept of prioritisation using the classical techniques of Pareto and $\mathrm{ABC}$ analysis as integrating elements to the traditional Taguchi method. The idea adopted is that factors engaged in the analysis do not have the same importance in the process. Furthermore, it is opined that by identifying factors with a high priority will help us divert attention and resources for effective usage in the face of scarce resources.

\section{Literature review}

\subsection{Extant literature review concerning A356 alloy}

In the A356 alloy composite literature, the A356 alloy acts as the matrix element whose primary role is to hold the reinforcement that is added to the molten A356 together. It is anticipated that the A356 alloy displays outstanding properties in the tensile strength characteristics of composite, hardness, and confrontation to corrosion, among other strong composite and attractive aluminium matrix behaviour. As the aluminium matrix is the fundamental material that comes into contact straightforwardly with usage. For this work, the A356 alloy was chosen as the matrix for the composite while organic materials, mainly three, including pineapple sucker, Delonix regia and abori wood were of choice as reinforcements for the composite. A few authors have discussed the characteristics of A356 alloy as well as reinforcements when mixed with organic materials in view as reinforcements. The extant literature revealed a generous number of approaches that have been used to produce A356 composites, primarily solution heat treatment and age hardening [16]. A review of the literature is as follows.

Wei et al. [23] studied the contribution of yttrium, a rare earth element with the extrusion process at high temperature to the microstructure and mechanical qualities or A356 alloy using mechanical properties and microstructure examination. The outcome of their findings shows that introducing yttrium enhanced the microstructure of A356 cast alloy L-Al proportion are evenly good and well arranged. The average diameter was found to be $40.3 \mathrm{~nm}$ while the aspect ratio hits the least with $68.9 \%$ and $82.1 \%$ lesser than that void yttrium. Wu et al. [21] made Al-5Sr-8Ce alloy as a special innovative enhancer for A356. The influence of it on the microstructure and tensile qualities of A356 was experimentally researched with optimisation of enhancement period by modification efficiency. It was concluded that $0.4 \% \mathrm{Al}-5 \mathrm{Cr}-8 \mathrm{Ce}$ reduced enhancement time to 90 minutes.

Kumar et al. [11] reinforced A356 with bagasse ash in proportion 2 to $10 \%$ step 2 by stir casting method in other to analyse the density, microstructure and mechanical properties of the plain alloy and the reinforced alloy. The density of the composites reduces as the content of ash rises. Using as-cast nanostructure, the ash was evenly mixed. It was confirmed that bagasse ash particles reinforced composite is capable to improve properties and give reduced density to A356 alloy.

Jalilvand et al. [24] fabricated nanocomposites film strengthened with nanosized $\mathrm{Al}_{2} \mathrm{O}_{3}$ and $\mathrm{S}_{\mathrm{i}} \mathrm{O}_{2}$ powder in A356 cast aluminium medium by friction stir processing (FSP). The FSP of the samples resolved in coarse silicon needle-shaped and primary aluminium fragmentation with a decline in holes and an even shear of silicon in the aluminium substrate. Also, the microstructural analysis indicates an even distribution of strengthening in the nugget region. The superficial mix nanocomposites gave an improved mechanical and corrosion responses to A356 Al alloy and the FSP A356 composites. Nayak and Venugopal [25] obtained a shrinkage allowance for H-sharp A356 alloy via investment casting. These

e-ISSN: 2289-7771

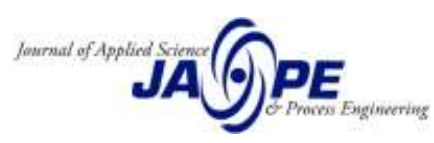


types of $\mathrm{H}$-shape casting were subjected to test to obtain their free and restricted shrinkage. From the obtained result free and restricted shrinkage allowance factor forms a linear relationship. Cui et al. [26] set up an innovative $\mathrm{Al}-3 \mathrm{~B}-5 \mathrm{Sr}$ master alloy via an in-situ blend approach in $\mathrm{Al}$ melt. The outcome revealed that the $\mathrm{Al}-3 \mathrm{~B}-5 \mathrm{Sr}$ alloy chiefly contains phases of $\alpha-\mathrm{Al}$ and coarse $\mathrm{SrB}_{6}$, whereas the $\mathrm{Al}-3 \mathrm{~B}-5 \mathrm{Sr}-7 \mathrm{Si}$ alloy comprised asymmetrical blocky $\mathrm{Al}_{4} \mathrm{Sr}$ phase, $\mathrm{AlB}_{2}$ and $\mathrm{Si}$ apart from the above-declared phases. Ma and Carneiro et al. [18] explored the effect of thermal enhancement in the microstructure of A356 in ceramic block relating the morphology changes with the mechanisms within the alloy that favours the yield strength and brings down dumping. Elahi and Shabestari [17] investigated the microstructure and impact response of A356 aluminium alloy at post melt enhanced and T6 thermal enhancement state. The outcome of the experiment makes eutectic silicon morphology the main factor to regulate the impact response of alloy. Changes in tensile characteristics of A356 alloy at varying temperatures, between $20^{\circ} \mathrm{C}$ and $-60^{\circ} \mathrm{C}$ was researched by Ma et al. [27]. The structural shift arrangement around the crack surface was analysed by scanning electron microscopy (SEM). Yang et al. [16] studied the influence of cooling rate on solution heat treatment of as-cast A356 alloy. Kumar et al. [28] employed Taguchi experimental design and 30 simulations in suggesting the semi-solid state movement of alloy as well as analyze the thrxo forging properties of semi-solid A356 alloy. Taguchi experimental analysis revealed $580^{\circ} \mathrm{C}$ as the most effective thixo forging temperature with 0.5 solid content or $40 \%$ deformation and $200^{\circ} \mathrm{C}$ temperature die hotness degree.

Long et al. [29] studied the implication of mixture enhancement on age hardening of A356 Al$70 \mathrm{Si}-0.3 \mathrm{Mg}$ alloy by evaluating the hardness and microscopy election. Experimental findings revealed that $\mathrm{Mg}$ atoms migrate to the holes in A356 as solution treatment continued. Vencl et al. [30] studied the A356 Al-Si alloy (matrix) to produce metal matrix composites employing the procedure of compocasting. The particles, namely graphite, $\mathrm{SiC}$ and $\mathrm{Al}_{2} \mathrm{O}_{3}$ were added to the matrix. The authors analysed and weighed the test results of tribological properties and hardness concerning the heat-treated (T6) specimens against one another. In conclusion, wear confrontation of composites fortified with SiC particulates was superior and frictional coefficient was less weighed against the composite fortified with $\mathrm{Al}_{2} \mathrm{O}_{3}$ particles. The composite (having $\mathrm{SiC}$ as well as graphite particulates) revealed the least quantity of wear rate and frictional coefficient. Also, the leading wear system for all experimented materials was adhesion. Ochieze et al. [12] prepared A356 alloy reinforced with cow horn particles made by spark plasma sintering and experimented the wear properties using the Taguchi $\mathrm{L}_{9}$ method. It was observed that the strengthened A356 alloy possessed a dry sliding wear resistance preferred to the plain A356 alloy. In Staia et al. [31], the laser alloying of sand cast Al alloy A356 together with tungsten employing a two-phase method of laser alloying was performed. The conclusion was that the laser treated surfaces offered a growth in wear confrontation between $40 \%$ as well as almost $110 \%$ when weighed against the wear confrontation of the untreated $\mathrm{Al}$ alloy, as well as the enhancement was comparative to the laser beam- substrate interaction time. Kumar et al. [32] established an applied study concerning Taguchi's experimental design scheme to analyse the wear characteristics of insitu-created $\mathrm{A}_{356}-5 \mathrm{TiB}_{2}$ composite under the thixoforming. The outcome of the research revealed that the impact velocity is the largely substantial factor and makes up to $42.31 \%$ of the complete influence on the rate of erosion for the thixoformed $\mathrm{A} 356-5 \mathrm{TiB}_{2}$ composite. It was revealed that material loss in the course of erosive wear was mainly because of microploughing and microfracture. Hashemi et al. [33] prepared coatings of Ni-2.5 wt-\% Palloy and a composite coating of Ni$5 \mathrm{wt}-\% \mathrm{P}-\mathrm{SiC}$ on A356 aluminium alloy. The outcome attained showed that a crack-liberated and uniform coating could be prepared by employing the most advantageous bath method. The composite coating was largely confrontational to wear weighed against the less phosphorus nickel one, however had reduced adhesion.

\subsection{Gaps noted in the literature}

As a result of a wide search of literature related to A356 alloy composite, some interesting gaps were noted and are subsequently stated as follows:

e-ISSN: 2289-7771

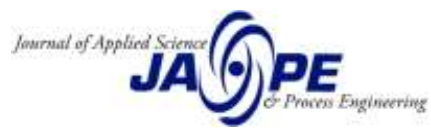


1. Researchers analysed the heat treatment aspect of the A356 alloy and A356 alloy reinforced with organic matter. Nonetheless, these are limited investigations on cow horn reinforced A356 alloy.

2. Literature review reveals that the A356 alloy reinforced with organic matter is a comparatively new aspect of composite development and extensive work has not been done in this area.

3. Previous research on the A356 alloy reinforced with the organic matter has not addressed the Taguchi optimisation issue.

4. Taguchi method has been recognised in the A356 alloy composite literature as an effective tool to attain optimality, as demonstrated by Kumar et al. [28]. However, to the best of our knowledge, it is the only known paper on the subject of A356 composite and more validations are required. Also, more robust frameworks of Taguchi methods that can concurrently tackle prioritisation of factors with the competence to optimise the melting and solidification system of A356 alloy composite for dimensional analysis and optimisation are required.

5. A combination of tools and techniques such as optimisation and simulation tools has been reported as effective in the A356 alloy literature. For instance, Kumar et al. [28] combined experimental design concept and simulation in a study to advocate for the synergic advantages of optimisation and simulation.

\section{Methodology}

\subsection{Process taken to produce the aluminium cast (canoe-shaped sample) (Figure 1)}

3.1.1 Preparing the Furnace (local)

(1) The furnace is made up of the burner, used oil tank, steel pot, steel cover (vehicle wheel), a tong and an electric blower

(2) The burner which extends from the ground is levelled at its ground level using sand and also stones were placed to stabilize the steel pot to be placed inside it.

(3) The used oil level is checked, and more used oil is added into the tank which has a sieve at its top to remove impurities from the used oil when it has been poured inside. The used oil tank is connected to the with a hose and a funnel (one end of the hose has a funnel on it placed at the mouth of the tap at the used oil tank and the other connects to the burner.

(4) The electric blower is also connected to the burner using a steel pipe. The electric blower provides air for the burner to aid in the burning.

(5) The pot is then placed in the burner, woods are then broken into smaller pieces and placed beside the pot in the burner and a little-used oil is poured into the burner using a small plastic bucket.

3.1.2 Melting and Casting of the aluminium scraps

(1) The aluminium scrap is weighed on a Camry emperor scale which read 30kg. The aluminium scrap is broken into a sizable unit for the burning pot.

(2) At 3:18 pm, fire is then lit in the burner, used oil is poured into it and continues to increase the burning. The already broken aluminium scrap is placed inside the pot using a tong. The Electric blower that is already connected to the burner is switched on by connecting its wire to a socket, then switch on the socket. The tap of the tank that contains the used oil is opened.

(3) The aluminium scrap started to melt at 3:39 pm. The burner is covered by placing the steel wheel over the burner using a tong to carry it.

(4) As the metal is melting, the mould is made using a canoe-shaped pattern. The sand for casting is prepared by softening the sand using hands, the pattern is placed into the sand and a plump was used to level the pattern with the ground, the sand is then packed around the pattern, brush is used to remove sand on top of the pattern, scalp and foam soaked in water was used to smoothen the part of the sand touching the sides of the pattern. The pattern is removed from the sand to form the mould. It took 10-12 minutes to make a mould. As the other moulds were made another personnel stirs the melting metals and added more aluminium scrap to it.

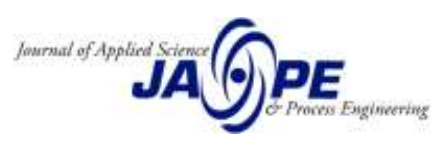




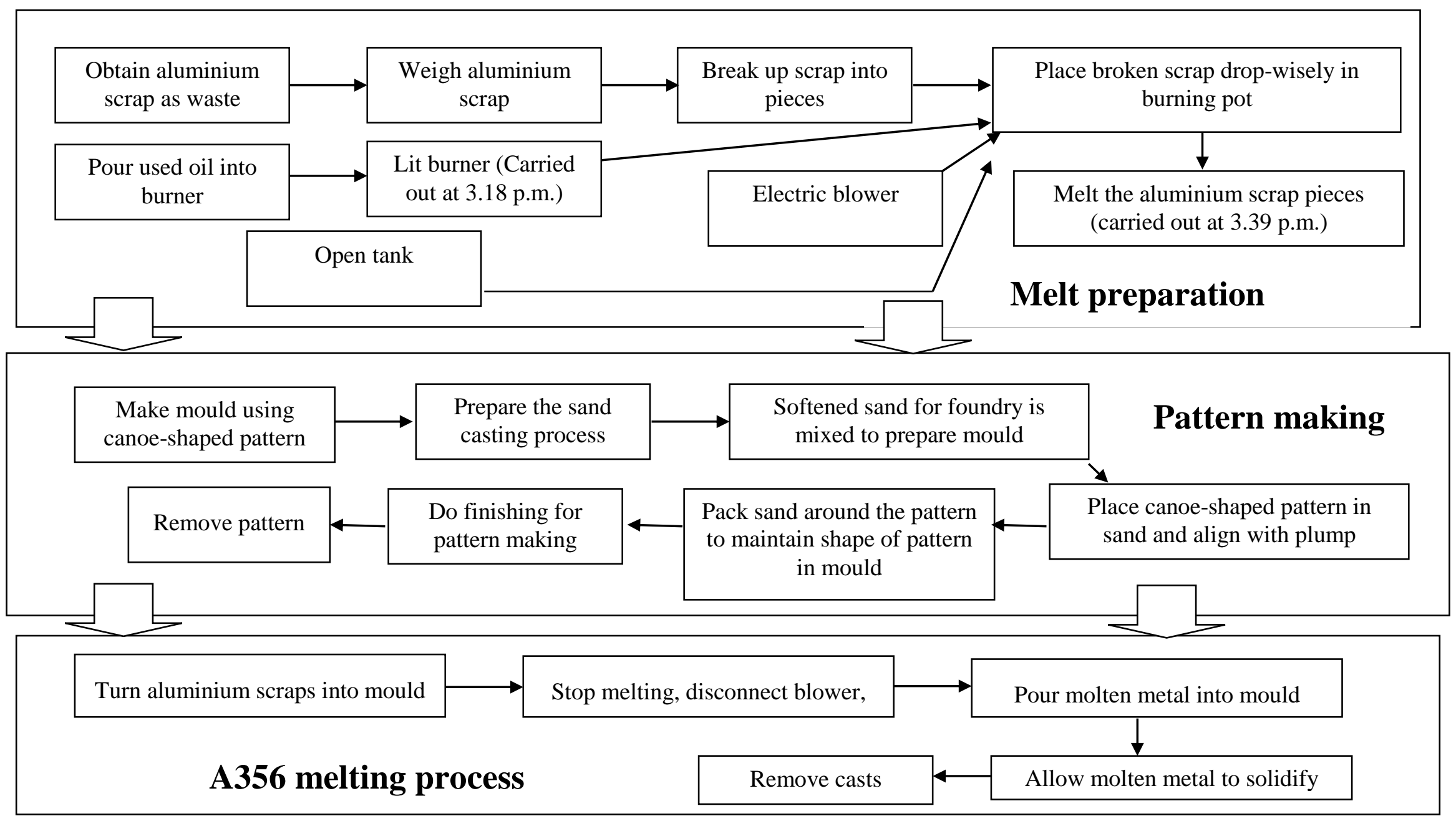

Figure 1. Preparation of casts 1 and 2 in melting and solidification by sand casting method 
(5) The whole aluminium scrap had turned in to molten the slag in the molten was scooped out using a small steel plate held with a tong. The molten metal is then stirred continuously.

(6) After melting the aluminium scrap and making all the moulds, the molten metal was then poured into the moulds using a small steel plate held with a tong. Ten moulds were made in a canoeshaped form and one mould was shapeless. After pouring the molten metal into each mould (it took 2 minutes to carry the molten from the steel pot and into the mould). It took 10-15 minutes to solidify, then left to cool.

(7) The melting stopped at around 4:55 pm, the blower is disconnected from the socket and a tong was used to carry out the steel pot from the burner. The fire is the burner is then quenched.

\subsection{Dimensional issues concerning the melted and solidified canoe-shaped samples}

The casting of materials and its dimensional analysis is in two phases, including the canoe-shaped cast (phase 1) and relating to the cuboid-shaped cast (phase 2). The method, as well as materials and equipment, are subsequently discussed here.

\section{Phase 1 (Canoe-shaped cast)}

Materials/equipment

For this cast category, the following items are used in the process

- Counterbalance weight scale, Electronic weight machine, Two buckets (a medium-sized bucket to about 14 litres, and a large bucket), Measuring cylinder

Experimental description

Weight measurement: Nine samples of the canoe-shaped casts were obtained from the counterbalance weighing machine. The process of weighing each canoe-shape cast sample involves putting each sample on the machine. As it passes the $500 \mathrm{~g}$ mark, weight is then added at the opposite side of the scale to balance the weight of the sample. For the first sample, when placed on the scale it passed the $500 \mathrm{~g}$ mark and extra weight of $1 \mathrm{~kg}$ was placed at the other side till it passed the $500 \mathrm{~g}$ mark. Notice that the other weight of $0.5 \mathrm{~kg}(500 \mathrm{~g})$ is placed at the other side to add up to $1.5 \mathrm{~kg}$. The side of the sample read $308 \mathrm{~g}$, which makes the weight of the sample $1.808 \mathrm{~kg}$. This was done for the remaining eight samples and the control sample as well as the aluminium cast product and slag

Density measurement: For the density of samples, two buckets were involved, which are first weighed. The smaller bucker is then filled with water and placed into the larger bucket such that as the sample is fully submerged in the water, it pours out the extra water equivalent to the volume of the sample. It should be noted that the smaller bucket is filled to the maximum level such that a slight displacement of the water will pour out the extra water. So the first sample was placed inside the bucket filled with water (fully immersed) and water (where the sample was placed) fell out from the bucket. The larger bucket which contains the water from the medium bucket when the sample was placed inside it is weighed. Then the volume of water in the large bucket is checked using a measuring cylinder. The volume obtained is as well taken as the volume of the sample assuming that losses are negligible. The density of the sample is then obtained by dividing the mass/weight of the sample by the volume obtained. The process is as well conducted for the remaining samples, control, and the aluminium cast product and the slag. A second experiment was conducted on the plate cast to determine the dimension of the samples. In this experiment, the following materials/equipment were used: Ruler, electronic weighing machine, two buckets and measuring cylinder. 


\section{Phase 2 (Cuboid-shaped cast)}

Description of the experiment

Measurement of length, breadth, and width: The ruler was used to obtain the length, breadth, and width of the samples, excluding the control, the aluminium cast product and the slag

Weight: The weight of each sample was obtained using the electronic weighing machine. The sample is placed on the weighing scale and the reading shown is the weight of the sample. This was done for the other eight samples

Density: The two buckets are first weighed after weighing the medium bucket, and then filled with water, and subsequently placed into the large bucket (Figure 2). A sample is placed inside the bucket filled with water (fully immersed), water coming out of the bucket filled with water (where the sample was placed) is then brought out from the large bucket. The larger bucket which contains the water from the medium bucket where the sample was placed is weighed. Then the volume of water in the large bucket is checked using the measuring cylinder and the volume obtained is also the volume of the sample placed in the medium bucket. The density of the sample is obtained by dividing the mass/weight of the sample with the volume obtained. This procedure is carried out for the other eight samples

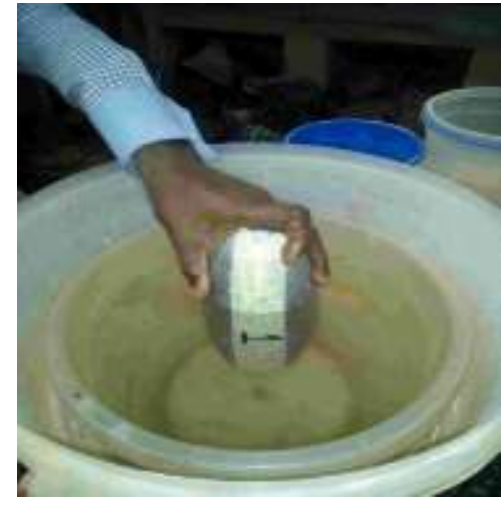

(a)

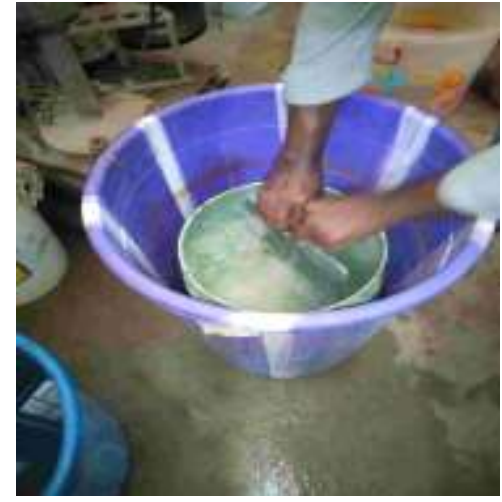

(b)

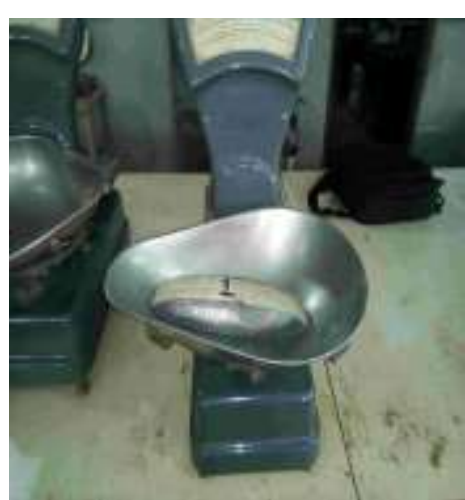

(c)

Canoe-shaped sample inserted in water for displacement

Cuboid-shaped inserted in water for displacement sample

Canoe-shaped sample being weighed on machine

Figure 2. Samples being measured in water and on a scale

\subsection{Organic materials}

The information in Table 1 reveals the weight of the complete organic materials used in this work.

Table 1. Total weight of organic material infused in each sample

\begin{tabular}{|c|r|r|r|r|}
\hline \multicolumn{5}{|l|}{ Table 1. Total weight of organic material infused in each sample } \\
\hline Sample & $\begin{array}{l}\text { Weight of } \\
\text { Pineapple sucker } \\
(\mathrm{g})\end{array}$ & $\begin{array}{l}\text { Weight of } \\
\text { Abori wood }(\mathrm{g})\end{array}$ & $\begin{array}{l}\text { Weight of Delonix } \\
\text { regia }(\mathrm{g})\end{array}$ & $\begin{array}{l}\text { Total weight of } \\
\text { Organic materials } \\
(\mathrm{g})\end{array}$ \\
\hline 1 & 135.6 & 81.36 & 54.24 & 271.2 \\
\hline 2 & 118.6 & 88.95 & 88.95 & 296.5 \\
\hline 3 & 85.95 & 143.25 & 57.3 & 286.5 \\
\hline 4 & 70.43 & 46.95 & 55.76 \\
\hline 5 & 111.75 & 55.88 & 116.44 & 223.51 \\
\hline 6 & 58.22 & 58.22 & 55.33 & 232.88 \\
\hline 7 & 55.33 & 110.65 & 95.25 & 221.31 \\
\hline 8 & 38.3 & 57.45 & 37.3 & 191 \\
\hline 9 & 74.6 & 74.6 & & 186.5 \\
\hline
\end{tabular}

\subsection{Taguchi method}

e-ISSN: 2289-7771 
Taguchi method is an effective tool for running process and system optimisation, mostly since other optimisation method works with only one factor at a time. The signal to noise ratio approach is the main part of the Taguchi method, which stands as the statistical evaluation of the logarithmic terms of the foreseeable goal of the experiment. Signal factors present the average operation of the method, while noise factors are factors that are complex and hard to operate. Taguchi method has three designs, which are system design which allows the selection of suitable operational levels that defines the states of the parameters in the experiment, the parametric design that facilitates in the identification of factor levels that produce the ideal operation of the process and then the tolerance design which is employed to lower the tolerance of factors that produce meaningful impact to the system [22]. The parametric design is employed in this work to get the ideal set of parameters. The "smaller-the-best" (SB), the "larger-the-best" (LB) and the "nominal-the-best" quality characteristics are employed in the Taguchi method. For this experiment, "smaller-the-best" is selected to the quality characteristics. The objective function is expressed corresponding to the smaller-the-best quality characteristics in Equation (1) [22, 34-36].

$$
\mathrm{S} / \mathrm{N}=-10 \log 10\left(1 / \mathrm{n} \sum_{i=1}^{n} x_{i}^{2}\right)
$$

where $\mathrm{S} / \mathrm{N}$ is the signal to noise ratio of the system, $n$ is the number of the experiment in all trial settings and $x_{i}$ is the evaluated value of the smaller-the-best quality characteristics. Eleven parameters which are Volume of cast $1\left(\mathrm{~m}^{3}\right)$, Length of cast $1(\mathrm{~m})$, Weight of cast $1(\mathrm{~kg})$, Density of cast $1\left(\mathrm{~kg} / \mathrm{m}^{3}\right)$, Height of cast $1(\mathrm{~m})$, Width of cast $1(\mathrm{~m})$, Weight of cast $2(\mathrm{~kg})$, Length of cast $2(\mathrm{~m})$, Breadth of cast $2(\mathrm{~m})$, Weight loss $(\mathrm{kg})$, Total weight of organic materials $(\mathrm{kg})$ as shown in Table 1 were used to get three different parameters and levels (Table 2). The orthogonal array is shown in Table 3

\begin{tabular}{|c|c|c|c|c|c|c|c|c|c|c|}
\hline \multirow[b]{2}{*}{ S/No } & \multirow[b]{2}{*}{ Parameters } & \multicolumn{3}{|c|}{ Levels $^{\mathrm{a}}$} & \multicolumn{3}{|c|}{ Levels $^{\mathrm{b}}$} & \multicolumn{3}{|c|}{ Levels $^{\mathrm{c}}$} \\
\hline & & 1 & 2 & 3 & 1 & 2 & 3 & 1 & 2 & 3 \\
\hline 1 & $\begin{array}{l}\text { Volume of cast } 1 \\
\text { ( } \mathrm{m} \text { cube) }\end{array}$ & 0.000446 & 0.000381 & 0.000471 & 0.000424 & 0.000238 & 0.00033 & 0.000479 & 0.000544 & 0.000674 \\
\hline 2 & $\begin{array}{l}\text { Length of cast } 1(\mathrm{~m}) \\
\text { Weight of cast } 1\end{array}$ & 0.286 & 0.282 & 0.286 & 0.281 & 0.28 & 0.285 & 0.291 & 0.285 & 0.287 \\
\hline 3 & $(\mathrm{~kg})$ & 1.898 & 1.826 & 1.998 & 1.808 & 1.788 & 1.865 & 1.975 & 1.863 & 2.215 \\
\hline 4 & Density of cast 1 & 4271.1 & 5379.9 & 4545.1 & 3774.5 & 3452.2 & 3283.4 & 4658 & 7512.6 & 5803 \\
\hline 6 & $\begin{array}{l}\text { Width of cast } 1(\mathrm{~m}) \\
\text { Weight of cast } 2\end{array}$ & 0.101 & 0.097 & 0.1 & 0.096 & 0.095 & 0.096 & 0.103 & 0.099 & 0.106 \\
\hline 7 & $(\mathrm{~kg})$ & 1.77 & 1.68 & 1.83 & 1.72 & 1.58 & 1.7 & 1.84 & 1.74 & 2.04 \\
\hline 8 & $\begin{array}{l}\text { Length of cast } 2(\mathrm{~m}) \\
\text { Breadth of cast } 2\end{array}$ & 0.264 & 0.264 & 0.264 & 0.264 & 0.262 & 0.264 & 0.265 & 0.265 & 0.264 \\
\hline 9 & $(\mathrm{~m})$ & 0.240 & 0.241 & 0.24 & 0.24 & 0.24 & 0.24 & 0.241 & 0.241 & 0.24 \\
\hline 10 & $\begin{array}{l}\text { Weight loss }(\mathrm{kg}) \\
\text { Total weight of } \\
\text { Organic materials }\end{array}$ & 0.131 & 0.146 & 0.172 & 0.088 & 0.088 & 0.125 & 0.17 & 0.208 & 0.215 \\
\hline 11 & $(\mathrm{~kg})$ & 0.2847 & 0.230 & 0.1996 & 0.2712 & 0.22351 & 0.1865 & 0.2965 & 0.23476 & 0.22131 \\
\hline
\end{tabular}

e-ISSN: 2289-7771

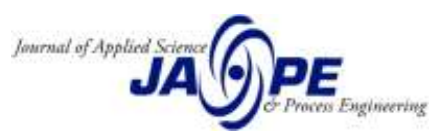


Table 3. Data used to obtain parameters and levels

\begin{tabular}{|r|r|r|r|r|r|r|r|r|r|r|r|}
\hline \multicolumn{1}{|c|}{ S/No. } & \multicolumn{1}{|c|}{$\mathrm{A}$} & $\mathrm{B}$ & $\mathrm{C}$ & $\mathrm{D}$ & $\mathrm{E}$ & $\mathrm{F}$ & $\mathrm{G}$ & $\mathrm{H}$ & $\mathrm{I}$ & $\mathrm{J}$ & $\mathrm{K}$ \\
\hline 1 & 0.000479 & 0.281 & 1.808 & 3774.5 & 0.036 & 0.096 & 1.72 & 0.265 & 0.24 & 0.088 & 0.2712 \\
\hline 2 & 0.000424 & 0.291 & 1.975 & 4658 & 0.039 & 0.103 & 1.84 & 0.264 & 0.24 & 0.135 & 0.2965 \\
\hline 3 & 0.000436 & 0.285 & 1.91 & 4380.7 & 0.038 & 0.103 & 1.74 & 0.264 & 0.241 & 0.17 & 0.2865 \\
\hline 4 & 0.000544 & 0.285 & 1.828 & 3452.2 & 0.036 & 0.098 & 1.74 & 0.264 & 0.241 & 0.088 & 0.23476 \\
\hline 5 & 0.000238 & 0.28 & 1.788 & 7512.6 & 0.036 & 0.095 & 1.58 & 0.265 & 0.241 & 0.208 & 0.22351 \\
\hline 6 & 0.00036 & 0.282 & 1.863 & 5175 & 0.037 & 0.099 & 1.72 & 0.262 & 0.24 & 0.143 & 0.23288 \\
\hline 7 & 0.000674 & 0.287 & 2.215 & 3283.4 & 0.04 & 0.106 & 2.04 & 0.264 & 0.24 & 0.175 & 0.22131 \\
\hline 8 & 0.00033 & 0.285 & 1.915 & 5803 & 0.038 & 0.098 & 1.7 & 0.264 & 0.24 & 0.215 & 0.191 \\
\hline 9 & 0.00041 & 0.285 & 1.865 & 4548.8 & 0.038 & 0.096 & 1.74 & 0.264 & 0.24 & 0.125 & 0.1865 \\
\hline
\end{tabular}

Key: A - Volume of cast 1 (m cube); B - length of cast $1(\mathrm{~m}) ; \mathrm{C}$ - weight of cast 1 (kg); D - Density of cast 1; E - Height of cast 1 (m); F - Width of cast $1(\mathrm{~m}) ; \mathrm{G}$ - weight of cast $2(\mathrm{~kg}) ; \mathrm{H}$ - length of cast $2(\mathrm{~m}) ; \mathrm{I}$ - breadth of cast $2(\mathrm{~m}) ; \mathrm{J}$ - weight loss (kg); K - Total weight of organic materials $(\mathrm{kg})$

$\mathrm{L}_{27}$ orthogonal array was picked for undergoing the experimental design with a Minitab 16 statistical software package can also be obtained using;

$$
L_{a}\left(b^{c}\right)
$$

where $L$ is Latin square, a is the number of tests (row), b is the number of levels and $\mathrm{c}$ is the number of parameters (column) (Table 4).

Table 4. $\mathrm{L}_{27}$ Orthogonal array

\begin{tabular}{|r|r|r|r|r|r|r|r|r|r|r|r|r|r|r|r|r|r|r|r|r|r|r|r|r|}
\hline S/N & $\mathbf{1}$ & $\mathbf{2}$ & $\mathbf{3}$ & $\mathbf{4}$ & $\mathbf{5}$ & $\mathbf{6}$ & $\mathbf{7}$ & $\mathbf{8}$ & $\mathbf{9}$ & $\mathbf{1 0}$ & $\mathbf{1 1}$ & $\mathbf{S} / \mathbf{N}$ & $\mathbf{1}$ & $\mathbf{2}$ & $\mathbf{3}$ & $\mathbf{4}$ & $\mathbf{5}$ & $\mathbf{6}$ & $\mathbf{7}$ & $\mathbf{8}$ & $\mathbf{9}$ & $\mathbf{1 0}$ & $\mathbf{1 1}$ \\
\hline $\mathbf{1}$ & 1 & 1 & 1 & 1 & 1 & 1 & 1 & 1 & 1 & 1 & 1 & $\mathbf{1 5}$ & 2 & 2 & 3 & 1 & 3 & 1 & 2 & 1 & 2 & 3 & 2 \\
\hline $\mathbf{2}$ & 1 & 1 & 1 & 1 & 2 & 2 & 2 & 2 & 2 & 2 & 2 & $\mathbf{1 6}$ & 2 & 3 & 1 & 2 & 1 & 2 & 3 & 3 & 1 & 2 & 2 \\
\hline $\mathbf{3}$ & 1 & 1 & 1 & 1 & 3 & 3 & 3 & 3 & 3 & 3 & 3 & $\mathbf{1 7}$ & 2 & 3 & 1 & 2 & 2 & 3 & 1 & 1 & 2 & 3 & 3 \\
\hline $\mathbf{4}$ & 1 & 2 & 2 & 2 & 1 & 1 & 1 & 2 & 2 & 2 & 3 & $\mathbf{1 8}$ & 2 & 3 & 1 & 2 & 3 & 1 & 2 & 2 & 3 & 1 & 1 \\
\hline $\mathbf{5}$ & 1 & 2 & 2 & 2 & 2 & 2 & 2 & 3 & 3 & 3 & 1 & $\mathbf{1 9}$ & 3 & 1 & 3 & 2 & 1 & 3 & 2 & 1 & 3 & 2 & 1 \\
\hline $\mathbf{6}$ & 1 & 2 & 2 & 2 & 3 & 3 & 3 & 1 & 1 & 1 & 2 & $\mathbf{2 0}$ & 3 & 1 & 3 & 2 & 2 & 1 & 3 & 2 & 1 & 3 & 2 \\
\hline $\mathbf{7}$ & 1 & 3 & 3 & 3 & 1 & 1 & 1 & 3 & 3 & 3 & 2 & $\mathbf{2 1}$ & 3 & 1 & 3 & 2 & 3 & 2 & 1 & 3 & 2 & 1 & 3 \\
\hline $\mathbf{8}$ & 1 & 3 & 3 & 3 & 2 & 2 & 2 & 1 & 1 & 1 & 3 & $\mathbf{2 2}$ & 3 & 2 & 1 & 3 & 1 & 3 & 2 & 2 & 1 & 3 & 3 \\
\hline $\mathbf{9}$ & 1 & 3 & 3 & 3 & 3 & 3 & 3 & 2 & 2 & 2 & 1 & $\mathbf{2 3}$ & 3 & 2 & 1 & 3 & 2 & 1 & 3 & 3 & 2 & 1 & 1 \\
\hline $\mathbf{1 0}$ & 2 & 1 & 2 & 3 & 1 & 2 & 3 & 1 & 2 & 3 & 1 & $\mathbf{2 4}$ & 3 & 2 & 1 & 3 & 3 & 2 & 1 & 1 & 3 & 2 & 2 \\
\hline $\mathbf{1 1}$ & 2 & 1 & 2 & 3 & 2 & 3 & 1 & 2 & 3 & 1 & 2 & $\mathbf{2 5}$ & 3 & 3 & 2 & 1 & 1 & 3 & 2 & 3 & 2 & 1 & 2 \\
\hline $\mathbf{1 2}$ & 2 & 1 & 2 & 3 & 3 & 1 & 2 & 3 & 1 & 2 & 3 & $\mathbf{2 6}$ & 3 & 3 & 2 & 1 & 2 & 1 & 3 & 1 & 3 & 2 & 3 \\
\hline $\mathbf{1 3}$ & 2 & 2 & 3 & 1 & 1 & 2 & 3 & 2 & 3 & 1 & 3 & $\mathbf{2 7}$ & 3 & 3 & 2 & 1 & 3 & 2 & 1 & 2 & 1 & 3 & 1 \\
\hline $\mathbf{1 4}$ & 2 & 2 & 3 & 1 & 2 & 3 & 1 & 3 & 1 & 2 & 1 & & & & & & & & & & & & \\
\hline
\end{tabular}

\section{Taguchi-Pareto Analysis}

The Pareto $80-20$ rule states that $20 \%$ of motives or reasons give $80 \%$ results. Pareto $80-20$ rule has been employed in different works of life, for instance, medical practice, statistics and economics. However its usage in solving casting problems has not been found in literature. In familiarising with the Taguchi method and the Pareto analysis, it was taken that a $20 \%$ factor level signified $80 \%$ of the whole aggregate percent to bring efficiency in optimality. This means that the factors and levels are not efficient to optimality and not contemplated for more studies. The adapted objective function of the optimisation is defined in Equation (3) [22, 34-36]:

$\mathrm{S} / \mathrm{N}=-10 \log 10\left(\frac{1}{n} \sum P_{80 / 20} x_{i}^{2}\right)$

where $\mathrm{S} / \mathrm{N}$ is the signal to noise ratio of the system, $n$ is the number of the experiment in every trial settings and $x_{i}$ is the evaluated value of the lower-the-best quality characteristics.

\section{Taguchi-ABC Analysis}

e-ISSN: 2289-7771 
The $\mathrm{ABC}$ category has been employed to position data or studies centred on their aggregate percentage of the total. Therefore, the studies which have an aggregate percentage of $66.6 \%$ to the total are selected as A. The studies which occupy $23.3 \%$ is regarded as B then the final study takes $10.1 \%$ is viewed as C.

$\mathrm{S} / \mathrm{N}=-10 \log 10\left(\frac{1}{n} A B C \sum x_{i}^{2}\right)$

where $\mathrm{S} / \mathrm{N}$ is the signal to noise ratio of the system, $n$ is the number of the experiment in every trial setting, $\mathrm{ABC}$ is the use of $\mathrm{ABC}$ classification to the factor levels and ${ }^{x_{i}}$ is the evaluated value of the lowerthe-best quality characteristics.

\section{Results and discussion}

In aluminium matrix composite design, analysis, and optimisation, there is a huge list of parameters to manage and this makes the solution space to be extremely challenging to explore to obtain satisfying values for the individual scenario under investigation. Furthermore, the optimisation of all the scenarios will be time-demanding. For some time now, several multi-goal solution approaches have emerged, including goal programming, and multi-criteria decision-making models. While these techniques are credible candidates for optimisation their drawbacks include their extremely high cost and timeconsuming computational procedures. Thus, the Taguchi methods appear to outsmart these techniques by overcoming the shortcoming in other techniques and therefore preferred in scientific discussions

\section{Taguchi method (TM)}

The Taguchi optimisation method that offers a statistical measure of the ratio between factors that governors the average operation of the system and factors which are bulky and complex to handle is the $\mathrm{S} / \mathrm{N}$ Ratio analysis, which is a well-defined aspect of the Taguchi optimisation method. Taguchi experimental design solves the influence of control factors on the $\mathrm{S} / \mathrm{N}$ ratio because of its statistical independence (Tables 5a,b,c). Table 6 shows the $\mathrm{S} / \mathrm{N}$ ratio response table of each parameter and level. The level that has the highest S/N Ratio shows that the disparity (variation) between the signal and the noise factor is low and is taken as the best level of the parameter.

\section{Analysis of variance}

Analysis of variance is a statistical method that is employed to calculate the singular influence of the governable factors on the quality characteristics [22]. The analysis of variance for the A356 alloy cast is shown in Table 7. At the instance of establishing the singular influence of the geometric factors on the responses of the three scenarios, the analysis of variance was used. The findings suggest that the density parameter for the canoe-shaped output (case 1) had the highest and major significance to the A356 alloy cast with a variance of 333573.5825 . The implication is that the addition of organic materials in the second phase of the casting via the cuboid-shaped pattern lowers the density of the final product. It then means that apart from the environmental friendliness objective, developing composites based on organic matters as reinforcements lowers the weight and attains the low-weight objective or desire of manufacturers and in particular the wheel tyre cover that is embarked upon in the larger project in which this paper is an aspect. The industry should deeply consider shifting away from reinforcing with only metals to reinforcing with organic matters in A356 alloy composite development. What follows density is the weight parameter of cast 1 , weight parameter of cast 2 , total weight of organic material parameter and weight loss parameter with variance values of $0.007491562,0.00544006,0.001859595$ and 0.000422933 respectively. The variance of other parameters was insignificant to the A356 alloy cast.

Table 5a. Taguchi $\mathrm{L}_{27}$ Experimental design for first parameter and level categories

e-ISSN: 2289-7771 


\begin{tabular}{|c|c|c|c|c|c|c|c|c|c|c|c|c|}
\hline S/N & $\mathrm{A}$ & B & $\mathrm{C}$ & $\mathrm{D}$ & $\mathrm{E}$ & $\mathrm{F}$ & $\mathrm{G}$ & $\mathrm{H}$ & I & $\mathrm{J}$ & $\mathrm{K}$ & S/N Ratio \\
\hline 1 & 0.000446 & 0.286 & 1.898 & 4271.1 & 0.038 & 0.101 & 1.77 & 0.264 & 0.24 & 0.131 & 0.2827 & -67.83958393 \\
\hline 2 & 0.000446 & 0.286 & 1.898 & 4271.1 & 0.036 & 0.097 & 1.68 & 0.264 & 0.241 & 0.146 & 0.2304 & -67.83958385 \\
\hline 3 & 0.000446 & 0.286 & 1.898 & 4271.1 & 0.039 & 0.1 & 1.83 & 0.264 & 0.24 & 0.172 & 0.1996 & -67.83958397 \\
\hline 4 & 0.000446 & 0.282 & 1.826 & 5379.9 & 0.038 & 0.101 & 1.77 & 0.264 & 0.241 & 0.146 & 0.1996 & -69.84427253 \\
\hline 5 & 0.000446 & 0.282 & 1.826 & 5379.9 & 0.036 & 0.097 & 1.68 & 0.264 & 0.24 & 0.172 & 0.2847 & -69.84427249 \\
\hline 6 & 0.000446 & 0.282 & 1.826 & 5379.9 & 0.039 & 0.1 & 1.83 & 0.264 & 0.24 & 0.131 & 0.2304 & -69.84427256 \\
\hline 7 & 0.000446 & 0.286 & 1.998 & 4545.1 & 0.038 & 0.101 & 1.77 & 0.264 & 0.24 & 0.172 & 0.2304 & -68.37965787 \\
\hline 8 & 0.000446 & 0.286 & 1.998 & 4545.1 & 0.036 & 0.097 & 1.68 & 0.264 & 0.24 & 0.131 & 0.1996 & -68.3796578 \\
\hline 9 & 0.000446 & 0.286 & 1.998 & 4545.1 & 0.039 & 0.1 & 1.83 & 0.264 & 0.241 & 0.146 & 0.2847 & -68.37965792 \\
\hline 10 & 0.000381 & 0.286 & 1.826 & 4545.1 & 0.038 & 0.097 & 1.77 & 0.264 & 0.241 & 0.172 & 0.2847 & -68.37965774 \\
\hline 11 & 0.000381 & 0.286 & 1.826 & 4545.1 & 0.036 & 0.1 & 1.68 & 0.264 & 0.24 & 0.131 & 0.2304 & -68.37965767 \\
\hline 12 & 0.000381 & 0.286 & 1.826 & 4545.1 & 0.039 & 0.101 & 1.83 & 0.264 & 0.24 & 0.146 & 0.1996 & $\begin{array}{l}-68.37965777 \\
\end{array}$ \\
\hline 13 & 0.000381 & 0.282 & 1.998 & 4271.1 & 0.038 & 0.097 & 1.83 & 0.264 & 0.24 & 0.131 & 0.1996 & -67.83958406 \\
\hline 14 & 0.000381 & 0.282 & 1.998 & 4271.1 & 0.036 & 0.1 & 1.77 & 0.264 & 0.24 & 0.146 & 0.2847 & -67.83958402 \\
\hline 15 & 0.000381 & 0.282 & 1.998 & 4271.1 & 0.039 & 0.101 & 1.68 & 0.264 & 0.241 & 0.172 & 0.2304 & -67.83958394 \\
\hline 16 & 0.000381 & 0.286 & 1.898 & 5379.9 & 0.038 & 0.097 & 1.83 & 0.264 & 0.24 & 0.146 & 0.2304 & -69.8442726 \\
\hline 17 & 0.000381 & 0.286 & 1.898 & 5379.9 & 0.036 & 0.1 & 1.77 & 0.264 & 0.241 & 0.172 & 0.1996 & -69.84427257 \\
\hline 18 & 0.000381 & 0.286 & 1.898 & 5379.9 & 0.039 & 0.101 & 1.68 & 0.264 & 0.24 & 0.131 & 0.2847 & -69.84427253 \\
\hline 19 & 0.000478 & 0.286 & 1.998 & 5379.9 & 0.038 & 0.1 & 1.68 & 0.264 & 0.24 & 0.146 & 0.2847 & -69.84427259 \\
\hline 20 & 0.000478 & 0.286 & 1.998 & 5379.9 & 0.036 & 0.101 & 1.83 & 0.264 & 0.24 & 0.172 & 0.2304 & -69.84427266 \\
\hline 21 & 0.000478 & 0.286 & 1.998 & 5379.9 & 0.039 & 0.097 & 1.77 & 0.264 & 0.241 & 0.131 & 0.1996 & -69.84427263 \\
\hline 22 & 0.000478 & 0.282 & 1.898 & 4545.1 & 0.038 & 0.1 & 1.68 & 0.264 & 0.24 & 0.172 & 0.1996 & -68.37965772 \\
\hline 23 & 0.000478 & 0.282 & 1.898 & 4545.1 & 0.036 & 0.101 & 1.83 & 0.264 & 0.241 & 0.131 & 0.2847 & -68.37965784 \\
\hline 24 & 0.000478 & 0.282 & 1.898 & 4545.1 & 0.039 & 0.097 & 1.77 & 0.264 & 0.24 & 0.146 & 0.2304 & -68.37965779 \\
\hline 25 & 0.000478 & 0.286 & 1.826 & 4271.1 & 0.038 & 0.1 & 1.68 & 0.264 & 0.241 & 0.131 & 0.2304 & -67.83958378 \\
\hline 26 & 0.000478 & 0.286 & 1.826 & 4271.1 & 0.036 & 0.101 & 1.83 & 0.264 & 0.24 & 0.146 & 0.1996 & -67.83958391 \\
\hline 27 & 0.000478 & 0.286 & 1.826 & 4271.1 & 0.039 & 0.097 & 1.77 & 0.264 & 0.24 & 0.172 & 0.2847 & -67.83958387 \\
\hline
\end{tabular}

Key: A - Volume of cast 1 (m cube); B - length of cast $1(\mathrm{~m}) ; \mathrm{C}$ - weight of cast 1 (kg); D - Density of cast 1; E - Height of cast 1 (m); F - Width of cast $1(\mathrm{~m}) ; \mathrm{G}$ - weight of cast $2(\mathrm{~kg}) ; \mathrm{H}$ - length of cast $2(\mathrm{~m}) ; \mathrm{I}$ - breadth of cast $2(\mathrm{~m}) ; \mathrm{J}$ - weight loss $(\mathrm{kg}) ; \mathrm{K}$ - Total weight of organic materials $(\mathrm{kg})$

\begin{tabular}{|c|c|c|c|c|c|c|c|c|c|c|c|c|}
\hline $\mathrm{S} / \mathrm{N}$ & A & B & $\mathrm{C}$ & $\mathrm{D}$ & $\mathrm{E}$ & $\mathrm{F}$ & $\mathrm{G}$ & $\mathrm{H}$ & $\mathrm{I}$ & $\mathrm{J}$ & $\mathrm{K}$ & S/N Dotic \\
\hline 1 & 0.000424 & 0.281 & 1.808 & 3774.5 & 0.036 & 0.096 & 1.72 & 0.264 & 0.24 & 0.088 & 0.2712 & -66.76574804 \\
\hline 2 & 0.000424 & 0.281 & 1.808 & 3774.5 & 0.036 & 0.095 & 1.58 & 0.262 & 0.24 & 0.088 & 0.22351 & -66.76574789 \\
\hline 3 & 0.000424 & 0.281 & 1.808 & 3774.5 & 0.038 & 0.096 & 1.7 & 0.264 & 0.24 & 0.125 & 0.1865 & -66.76574801 \\
\hline 4 & 0.000424 & 0.28 & 1.788 & 3452.2 & 0.036 & 0.096 & 1.72 & 0.262 & 0.24 & 0.088 & 0.1865 & $\begin{array}{l}-65.99070875 \\
\end{array}$ \\
\hline 5 & 0.000424 & 0.28 & 1.788 & 3452.2 & 0.036 & 0.095 & 1.58 & 0.264 & 0.24 & 0.125 & 0.2712 & -65.9907086 \\
\hline 6 & 0.000424 & 0.28 & 1.788 & 3452.2 & 0.038 & 0.096 & 1.7 & 0.264 & 0.24 & 0.088 & 0.22351 & -65.99070874 \\
\hline 7 & 0.000424 & 0.285 & 1.865 & 3283.4 & 0.036 & 0.096 & 1.72 & 0.264 & 0.24 & 0.125 & 0.22351 & -65.55526604 \\
\hline 8 & 0.000424 & 0.285 & 1.865 & 3283.4 & 0.036 & 0.095 & 1.58 & 0.264 & 0.24 & 0.088 & 0.1865 & -65.55526584 \\
\hline 9 & 0.000424 & 0.285 & 1.865 & 3283.4 & 0.038 & 0.096 & 1.7 & 0.262 & 0.24 & 0.088 & 0.2712 & -65.55526602 \\
\hline 10 & 0.000238 & 0.281 & 1.788 & 3283.4 & 0.036 & 0.095 & 1.72 & 0.264 & 0.24 & 0.125 & 0.2712 & -65.55526593 \\
\hline 11 & 0.000238 & 0.281 & 1.788 & 3283.4 & 0.036 & 0.096 & 1.58 & 0.262 & 0.24 & 0.088 & 0.22351 & -65.55526573 \\
\hline 12 & 0.000238 & 0.281 & 1.788 & 3283.4 & 0.038 & 0.096 & 1.7 & 0.264 & 0.24 & 0.088 & 0.1865 & -65.55526589 \\
\hline 13 & 0.000238 & 0.28 & 1.865 & 3774.5 & 0.036 & 0.095 & 1.7 & 0.262 & 0.24 & 0.088 & 0.1865 & -66.76574807 \\
\hline 14 & 0.000238 & 0.28 & 1.865 & 3774.5 & 0.036 & 0.096 & 1.72 & 0.264 & 0.24 & 0.088 & 0.2712 & -66.7657481 \\
\hline 15 & 0.000238 & 0.28 & 1.865 & 3774.5 & 0.038 & 0.096 & 1.58 & 0.264 & 0.24 & 0.125 & 0.22351 & -66.76574795 \\
\hline 16 & 0.000238 & 0.285 & 1.808 & 3452.2 & 0.036 & 0.095 & 1.7 & 0.264 & 0.24 & 0.088 & 0.22351 & -65.99070876 \\
\hline 17 & 0.000238 & 0.285 & 1.808 & 3452.2 & 0.036 & 0.096 & 1.72 & 0.264 & 0.24 & 0.125 & 0.1865 & -65.99070878 \\
\hline 18 & 0.000238 & 0.285 & 1.808 & 3452.2 & 0.038 & 0.096 & 1.58 & 0.262 & 0.24 & 0.088 & 0.2712 & -65.99070863 \\
\hline 19 & 0.00033 & 0.281 & 1.865 & 3452.2 & 0.036 & 0.096 & 1.58 & 0.264 & 0.24 & 0.088 & 0.2712 & -65.9907087 \\
\hline 20 & 0.00033 & 0.281 & 1.865 & 3452.2 & 0.036 & 0.096 & 1.7 & 0.262 & 0.24 & 0.125 & 0.22351 & -65.99070884 \\
\hline 21 & 0.00033 & 0.281 & 1.865 & 3452.2 & 0.038 & 0.095 & 1.72 & 0.264 & 0.24 & 0.088 & 0.1865 & -65.99070886 \\
\hline 22 & 0.00033 & 0.28 & 1.808 & 3283.4 & 0.036 & 0.096 & 1.58 & 0.262 & 0.24 & 0.125 & 0.1865 & -65.55526576 \\
\hline 23 & 0.00033 & 0.28 & 1.808 & 3283.4 & 0.036 & 0.096 & 1.7 & 0.264 & 0.24 & 0.088 & 0.2712 & -65.55526593 \\
\hline 24 & 0.00033 & 0.28 & 1.808 & 3283.4 & 0.038 & 0.095 & 1.72 & 0.264 & 0.24 & 0.088 & 0.22351 & -65.55526595 \\
\hline 25 & 0.00033 & 0.285 & 1.788 & 3774.5 & 0.036 & 0.096 & 1.58 & 0.264 & 0.24 & 0.088 & 0.22351 & -66.76574784 \\
\hline 26 & 0.00033 & 0.285 & 1.788 & 3774.5 & 0.036 & 0.096 & 1.7 & 0.264 & 0.24 & 0.088 & 0.1865 & $\begin{array}{l}-66.76574798 \\
\end{array}$ \\
\hline 27 & 0.00033 & 0.285 & 1.788 & 3774.5 & 0.038 & 0.095 & 1.72 & 0.262 & 0.24 & 0.125 & 0.2712 & -66.76574802 \\
\hline
\end{tabular}

Key: A - Volume of cast 1 (m cube); B - length of cast $1(\mathrm{~m}) ; \mathrm{C}$ - weight of cast 1 (kg); D - Density of cast 1; E - Height of cast 1 (m); F - Width of cast $1(\mathrm{~m}) ; \mathrm{G}$ - weight of cast $2(\mathrm{~kg}) ; \mathrm{H}$ - length of cast $2(\mathrm{~m}) ; \mathrm{I}$ - breadth of cast $2(\mathrm{~m}) ; \mathrm{J}$ - weight loss $(\mathrm{kg}) ; \mathrm{K}$ - Total weight of organic materials $(\mathrm{kg})$ 
Table 5c. Taguchi $\mathrm{L}_{27}$ Experimental design for third parameter and level categories

\begin{tabular}{|c|c|c|c|c|c|c|c|c|c|c|c|c|}
\hline $\mathrm{S} / \mathrm{N}$ & $\mathrm{A}$ & B & $\mathrm{C}$ & $\mathrm{D}$ & $\mathrm{E}$ & $\mathrm{F}$ & $\mathrm{G}$ & $\mathrm{H}$ & $\mathrm{I}$ & $\mathrm{J}$ & $\mathrm{K}$ & S/N Ratio \\
\hline 1 & 0.000479 & 0.291 & 1.975 & 4658 & 0.039 & 0.103 & 1.84 & 0.265 & 0.241 & 0.17 & 0.2965 & -68.59277866 \\
\hline 2 & 0.000479 & 0.291 & 1.975 & 4658 & 0.037 & 0.099 & 1.74 & 0.265 & 0.241 & 0.208 & 0.23476 & -68.59277859 \\
\hline 3 & 0.000479 & 0.291 & 1.975 & 4658 & 0.038 & 0.106 & 2.04 & 0.264 & 0.24 & 0.215 & 0.22131 & -68.59277881 \\
\hline 4 & 0.000479 & 0.285 & 1.863 & 7512.6 & 0.039 & 0.103 & 1.84 & 0.265 & 0.241 & 0.208 & 0.22131 & -72.74459332 \\
\hline 5 & 0.000479 & 0.285 & 1.863 & 7512.6 & 0.037 & 0.099 & 1.74 & 0.264 & 0.24 & 0.215 & 0.2965 & -72.7445933 \\
\hline 6 & 0.000479 & 0.285 & 1.863 & 7512.6 & 0.038 & 0.106 & 2.04 & 0.265 & 0.241 & 0.17 & 0.23476 & -72.74459338 \\
\hline 7 & 0.000479 & 0.287 & 2.215 & 5803 & 0.039 & 0.103 & 1.84 & 0.264 & 0.24 & 0.215 & 0.23476 & -70.50183998 \\
\hline 8 & 0.000479 & 0.287 & 2.215 & 5803 & 0.037 & 0.099 & 1.74 & 0.264 & 0.241 & 0.17 & 0.22131 & -70.50183993 \\
\hline 9 & 0.000479 & 0.287 & 2.215 & 5803 & 0.038 & 0.106 & 2.04 & 0.265 & 0.241 & 0.208 & 0.2965 & -70.50184008 \\
\hline 10 & 0.000544 & 0.291 & 1.863 & 5803 & 0.039 & 0.099 & 1.84 & 0.265 & 0.241 & 0.215 & 0.2965 & -70.50183979 \\
\hline 11 & 0.000544 & 0.291 & 1.863 & 5803 & 0.037 & 0.106 & 1.74 & 0.265 & 0.24 & 0.17 & 0.23476 & -70.50183974 \\
\hline 12 & 0.000544 & 0.291 & 1.863 & 5803 & 0.038 & 0.103 & 2.04 & 0.264 & 0.241 & 0.208 & 0.22131 & -70.50183989 \\
\hline 13 & 0.000544 & 0.285 & 2.215 & 4658 & 0.039 & 0.099 & 2.04 & 0.265 & 0.24 & 0.17 & 0.22131 & -68.59277901 \\
\hline 14 & 0.000544 & 0.285 & 2.215 & 4658 & 0.037 & 0.106 & 1.84 & 0.264 & 0.241 & 0.208 & 0.2965 & -68.59277887 \\
\hline 15 & 0.000544 & 0.285 & 2.215 & 4658 & 0.038 & 0.103 & 1.74 & 0.265 & 0.241 & 0.215 & 0.23476 & -68.59277879 \\
\hline 16 & 0.000544 & 0.287 & 1.975 & 7512.6 & 0.039 & 0.099 & 2.04 & 0.264 & 0.241 & 0.208 & 0.23476 & -72.74459342 \\
\hline 17 & 0.000544 & 0.287 & 1.975 & 7512.6 & 0.037 & 0.106 & 1.84 & 0.265 & 0.241 & 0.215 & 0.22131 & -72.74459336 \\
\hline 18 & 0.000544 & 0.287 & 1.975 & 7512.6 & 0.038 & 0.103 & 1.74 & 0.265 & 0.24 & 0.17 & 0.2965 & -72.74459333 \\
\hline 19 & 0.000674 & 0.291 & 2.215 & 7512.6 & 0.039 & 0.106 & 1.74 & 0.265 & 0.24 & 0.208 & 0.2965 & -72.74459341 \\
\hline 20 & 0.000674 & 0.291 & 2.215 & 7512.6 & 0.037 & 0.103 & 2.04 & 0.265 & 0.241 & 0.215 & 0.23476 & -72.74459349 \\
\hline 21 & 0.000674 & 0.291 & 2.215 & 7512.6 & 0.038 & 0.099 & 1.84 & 0.264 & 0.241 & 0.17 & 0.22131 & -72.74459343 \\
\hline 22 & 0.000674 & 0.285 & 1.975 & 5803 & 0.039 & 0.106 & 1.74 & 0.265 & 0.241 & 0.215 & 0.22131 & -70.5018398 \\
\hline 23 & 0.000674 & 0.285 & 1.975 & 5803 & 0.037 & 0.103 & 2.04 & 0.264 & 0.241 & 0.17 & 0.2965 & -70.50183995 \\
\hline 24 & 0.000674 & 0.285 & 1.975 & 5803 & 0.038 & 0.099 & 1.84 & 0.265 & 0.24 & 0.208 & 0.23476 & -70.50183984 \\
\hline 25 & 0.000674 & 0.287 & 1.863 & 4658 & 0.039 & 0.106 & 1.74 & 0.264 & 0.241 & 0.17 & 0.23476 & -68.5927785 \\
\hline 26 & 0.000674 & 0.287 & 1.863 & 4658 & 0.037 & 0.103 & 2.04 & 0.265 & 0.24 & 0.208 & 0.22131 & -68.59277873 \\
\hline 27 & 0.000674 & 0.287 & 1.863 & 4658 & 0.038 & 0.099 & 1.84 & 0.265 & 0.241 & 0.215 & 0.2965 & -68.59277858 \\
\hline
\end{tabular}

Key: A - Volume of cast 1 (m cube); B - length of cast $1(\mathrm{~m}) ; \mathrm{C}$ - weight of cast $1(\mathrm{~kg}) ; \mathrm{D}$ - Density of cast 1; E - Height of cast 1 (m); F - Width of cast $1(\mathrm{~m}) ; \mathrm{G}$ - weight of cast $2(\mathrm{~kg}) ; \mathrm{H}$ - length of cast $2(\mathrm{~m}) ; \mathrm{I}$ - breadth of cast $2(\mathrm{~m}) ; \mathrm{J}$ - weight loss $(\mathrm{kg}) ; \mathrm{K}$ - Total weight of organic materials $(\mathrm{kg})$ 
Table 6. Taguchi S/N Ratio response for first, second and third scenarios of parameter and level

\begin{tabular}{|c|c|c|c|c|c|c|c|c|c|c|c|}
\hline \multicolumn{12}{|c|}{ Taguchi S/N Ratio response for the first scenario of parameter and level } \\
\hline Level & A & $\mathrm{B}$ & $\mathrm{C}$ & $\mathrm{D}$ & $\mathrm{E}$ & $\mathrm{F}$ & $\mathrm{G}$ & $\mathrm{H}$ & $\mathrm{I}$ & $\mathrm{J}$ & $\mathrm{K}$ \\
\hline 1 & -68.6878381 & -68.68783809 & -68.68783809 & -67.83958393 & -68.68783809 & -68.68783811 & -68.6878381 & -68.68783809 & -68.6878381 & -68.68783809 & -68.6878381 \\
\hline 2 & -68.6878381 & -68.68783811 & -68.68783804 & -69.84427257 & -68.68783809 & -68.68783809 & -68.68783804 & -68.68783809 & -68.68783809 & -68.68783811 & -68.68783808 \\
\hline 3 & -68.68783809 & -68.68783809 & -68.68783817 & -68.37965779 & -68.68783811 & -68.68783809 & -68.68783815 & -68.68783811 & -68.6878381 & -68.68783809 & -68.68783811 \\
\hline Delta & 0.00000001 & 0.00000002 & 0.00000013 & 2.00468865 & 0.00000002 & 0.00000002 & 0.00000011 & 0.00000002 & 0.00000001 & 0.00000002 & 0.00000003 \\
\hline Rank & 11 & 5 & 2 & 1 & 5 & 5 & 3 & 5 & 11 & 5 & 4 \\
\hline \multicolumn{12}{|c|}{ Taguchi S/N Ratio response for the second scenario of parameter and level } \\
\hline Level & A & $\mathrm{B}$ & $\mathrm{C}$ & $\mathrm{D}$ & $\mathrm{E}$ & $\mathrm{F}$ & $\mathrm{G}$ & $\mathrm{H}$ & I & $\mathrm{J}$ & $\mathrm{K}$ \\
\hline 1 & -66.103984213 & -66.103984209 & -66.103984194 & -66.765977991 & -66.103984213 & -66.103984228 & -66.103984274 & -66.103984213 & -66.10398422 & -66.103984188 & -66.103984218 \\
\hline 2 & -66.103984205 & -66.103984206 & -66.103984168 & -65.990708741 & -66.103984189 & -66.103984213 & -66.103984109 & -66.103984189 & -66.10398422 & -66.103984227 & -66.103984196 \\
\hline 3 & -66.103984212 & -66.103984215 & -66.103984268 & -65.555265898 & -66.103984228 & -66.103984189 & -66.103984247 & -66.103984228 & -66.10398419 & -66.103984215 & -66.103984215 \\
\hline Delta & 0.000000008 & 0.000000009 & 0.000000101 & 1.210712092 & 0.000000038 & 0.000000038 & 0.000000166 & 0.000000039 & 0.000000031 & 0.000000038 & 0.000000022 \\
\hline Rank & 11 & 10 & 3 & 1 & 5 & 5 & 2 & 4 & 8 & 5 & 9 \\
\hline \multicolumn{12}{|c|}{ Taguchi S/N Ratio response for the third scenario of parameter and level } \\
\hline Level & $\mathrm{A}$ & B & $\mathrm{C}$ & $\mathrm{D}$ & $\mathrm{E}$ & $\mathrm{F}$ & $\mathrm{G}$ & $\overline{\mathrm{H}}$ & I & $\mathrm{J}$ & $\mathrm{K}$ \\
\hline 1 & $\begin{array}{l}-70.61307067 \\
\end{array}$ & -70.61307065 & -70.61307064 & -68.59277873 & -70.61307065 & -70.61307068 & -70.61307065 & -70.61307065 & $\begin{array}{l}-70.61307067 \\
\end{array}$ & -70.61307066 & -70.61307066 \\
\hline 2 & -70.61307069 & -70.6130707 & -70.61307058 & -72.74459338 & -70.61307066 & -70.61307065 & -70.6130706 & -70.61307066 & -70.61307065 & -70.61307068 & -70.61307064 \\
\hline 3 & -70.61307064 & -70.61307065 & -70.61307078 & -70.50183989 & -70.61307068 & -70.61307066 & -70.61307075 & -70.61307068 & -70.61307068 & -70.61307066 & -70.6130707 \\
\hline Delta & 0.00000005 & 0.00000005 & 0.00000020 & 4.15181466 & 0.00000003 & 0.00000003 & 0.00000015 & 0.00000003 & 0.00000003 & 0.00000002 & 0.00000006 \\
\hline Rank & 5 & 5 & 2 & 1 & 7 & 7 & 3 & 7 & 7 & 11 & 4 \\
\hline
\end{tabular}


Table 7. ANOVA Table for A356 alloy for three scenarios

\begin{tabular}{|c|c|c|c|c|c|c|c|}
\hline & \multicolumn{6}{|c|}{ Scenario 1} & \multirow{2}{*}{$\begin{array}{l}\text { Scenario } 2 \\
\text { Average }\end{array}$} \\
\hline & Summary & Count & Sum & Average & Variance & Sum & \\
\hline & A & 3 & 0.001298 & 0.000433 & $2.17386 \mathrm{E}-09$ & 0.000992 & 0.000331 \\
\hline & B & 3 & 0.853667 & 0.284556 & $4.9263 \mathrm{E}-06$ & 0.846 & 0.282 \\
\hline & $\mathrm{C}$ & 3 & 5.722333 & 1.907444 & 0.007491562 & 5.461 & 1.820333 \\
\hline & D & 3 & 14196.07 & 4732.022 & 333573.5825 & 10510.1 & 3503.367 \\
\hline & E & 3 & 0.112667 & 0.037556 & $1.9263 \mathrm{E}-06$ & 0.11 & 0.036667 \\
\hline & F & 3 & 0.298 & 0.099333 & $4.33333 \mathrm{E}-06$ & 0.287 & 0.095667 \\
\hline & G & 3 & 5.273667 & 1.757889 & 0.00544006 & 5 & 1.666667 \\
\hline & $\mathrm{H}$ & 3 & 0.792 & 0.264 & 0 & 0.79 & 0.263333 \\
\hline & I & 3 & 0.721 & 0.240333 & 3.33333E-07 & 0.72 & 0.24 \\
\hline & $\mathrm{J}$ & 3 & 0.448667 & 0.149556 & 0.000422933 & 0.301 & 0.100333 \\
\hline & K & 3 & 0.714303 & 0.238101 & 0.001859595 & 0.68121 & 0.22707 \\
\hline & Level 1 & 11 & 4276.11 & 388.7373 & 1658001.88 & 3779.305 & 343.5731 \\
\hline & Level 2 & 11 & 5384.702 & 489.5184 & 2630741.957 & 3456.793 & 314.2539 \\
\hline & Level 3 & 11 & 4550.192 & 413.6538 & 1877543.73 & 3288.2 & 298.9273 \\
\hline \multicolumn{8}{|c|}{ ANOVA } \\
\hline & $\begin{array}{l}\text { Source of } \\
\text { Variation }\end{array}$ & $S S$ & $D f$ & $M S$ & $F$ & $P$-value & $F$ crit \\
\hline \multirow[t]{6}{*}{ Scenario 1} & Rows & 61056350 & 10 & 6105635 & 201.3314089 & $8.19 \mathrm{E}-18$ & 2.347878 \\
\hline & Columns & 60621.37 & 2 & 30310.68 & 0.999485326 & 0.385724 & 3.492828 \\
\hline & Error & 606525.8 & 20 & 30326.29 & & & \\
\hline & Total & 61723497 & 32 & & & & \\
\hline & ANOVA & & & & & & \\
\hline & $\begin{array}{l}\text { Source of } \\
\text { Variation }\end{array}$ & SS & Df & MS & $\mathrm{F}$ & P-value & $F$ crit \\
\hline \multirow[t]{5}{*}{ Scenario 2} & Rows & 33464364 & 10 & 3346436 & 591.2703186 & $1.87 \mathrm{E}-22$ & 2.347878 \\
\hline & Columns & 11321.86 & 2 & 5660.93 & 1.000210267 & 0.38547 & 3.492828 \\
\hline & Error & 113194.8 & 20 & 5659.74 & & & \\
\hline & Total & 33588881 & 32 & & & & \\
\hline & ANOVA & & & & & & \\
\hline \multirow{5}{*}{ Scenario 3} & $\begin{array}{l}\text { Source of } \\
\text { Variation }\end{array}$ & SS & Df & MS & $\mathrm{F}$ & P-value & $F$ crit \\
\hline & Rows & 97876809.08 & 10 & 9787681 & 52.16820618 & $4.11 \mathrm{E}-12$ & 2.347878 \\
\hline & Columns & 375144.7692 & 2 & 187572.4 & 0.99975826 & 0.385628 & 3.492828 \\
\hline & Error & 3752354.787 & 20 & 187617.7 & & & \\
\hline & Total & 102004308.6 & 32 & & & & \\
\hline
\end{tabular}

\begin{tabular}{cccc} 
& \multicolumn{3}{c}{ Scenario 3} \\
\hline Variance & Sum & Average & Variance \\
\hline $.64933 \mathrm{E}-09$ & 0.001697 & 0.000566 & $9.85833 \mathrm{E}-09$ \\
0.001596333 & 0.863 & 0.287667 & $9.33333 \mathrm{E}-06$ \\
62258.32333 & 17973.6 & 2.017667 & 0.032341333 \\
$1.33333 \mathrm{E}-06$ & 0.116 & 0.0386667 & 2063749.72 \\
$3.33333 \mathrm{E}-07$ & 0.308 & 0.102667 & $1.23333 \mathrm{E}-06$ \\
0.005733333 & 5.62 & 1.873333 & 0.023333333 \\
$1.33333 \mathrm{E}-06$ & 0.794 & 0.264667 & $3.33333 \mathrm{E}-07$ \\
0 & 0.722 & 0.240667 & $3.33333 \mathrm{E}-07$ \\
0.000456333 & 0.593 & 0.197667 & 0.000586333 \\
0.001803028 & 0.75257 & 0.250857 & 0.001607711 \\
1294838.919 & 4663.221 & 423.9292 & 1972009.618 \\
1083138.025 & 7517.573 & 683.4158 & 5130153.754 \\
979778.9641 & 5808.629 & 528.0572 & 3060753.014
\end{tabular}


In this work, the mathematical expression of signal-to-noise $(\mathrm{S} / \mathrm{N})$ ratio, which is an indicator of the response variations occurring in the casting process data, is applied. The $\mathrm{S} / \mathrm{N}$ ratio is built on the characteristic of tie sand casting method concerning the geometric parameters of interest. For the analysis, the smaller-the-superior expression is chosen as it is desired to lessen the various sizes for compactness of the configuration. Consider the Taguchi S/N ratio response for the first, second and third scenarios of the parameter and level analysis (Table 6). The findings on the $\mathrm{S} / \mathrm{N}$ ratios suggest that the factor named as density of cast 1 is the most significant in all the scenarios considered as it resulted in the first place out of eleven positions. From the worst side, the volume of cast 1 has a tie with the weight loss. The implication of this result is as explained earlier when the variance results were analysed and the same density of cast 1 was chosen as the most significant factor. This means that item density of cast 1 has the largest influence on the responses and should be monitored.

The analysis of variance for the A356 alloy cast is shown in Table 7. The density parameter of cast 1 had the highest and major significant to the A356 alloy cast with a variance of 62258.32333 , followed by the weight parameter of cast 2 , the total weight of organic material parameter, weight parameter of cast 1 and weight loss parameter with variance values of $0.005733333,0.001803028,0.001596333$ and 0.000456333 respectively. The variance of other parameters was insignificant to the A356 alloy cast. The same parameters with that of the previous Table 7 are shown. However, finally, the analysis of variance for the A356 alloy cast in Table 7. The density parameter of cast 1 had the highest and major significant to the A356 alloy cast with a variance of 2063749.72 , followed by the weight parameter of cast 1 , weight parameter of cast 2, the total weight of organic material parameter and weight loss parameter with variance values of $0.032341333,0.001607711,0.001607711$ and 0.000586333 respectively. The variance of other parameters was also insignificant to the A356 alloy cast.

\section{Taguchi-Pareto Analysis}

The factor levels with significant variance are the $20 \%$ found to represent the $80 \%$ of total cumulative percentage which means that they are economical to optimality why the remaining are not. The number of factors is then reduced to 5 in each application as shown in Table 8. Table 9 shows the orthogonal array used in this analysis and Table 10 shows the Taguchi-Pareto $\mathrm{L}_{27} 3^{5}$ experimental design for A356 alloy cast for application 1 
Table 8. Taguchi-Pareto analysis parameter and levels for scenarios 1 to 3

\begin{tabular}{|c|c|c|c|c|c|c|c|c|c|c|}
\hline & & \multicolumn{3}{|c|}{ Scenario 1} & \multicolumn{3}{|c|}{ Scenario 2} & \multicolumn{3}{|c|}{ Scenario 3} \\
\hline $\mathrm{S} / \mathrm{N}$ & Parameters & 1 & 2 & 3 & 1 & 2 & 3 & 1 & 2 & 3 \\
\hline 1 & Weight of cast $1(\mathrm{~kg})$ & 1.898 & 1.826 & 1.998 & 1.808 & 1.788 & 1.865 & 1.975 & 1.863 & 2.215 \\
\hline 2 & Density of cast 1 & 4271.1 & 5379.9 & 4545.1 & 3774.5 & 3452.2 & 3283.4 & 4658 & 7512.6 & 5803 \\
\hline 3 & Weight of cast $2(\mathrm{~kg})$ & 1.77 & 1.68 & 1.83 & 1.72 & 1.58 & 1.70 & 1.84 & 1.74 & 2.04 \\
\hline 4 & Weight loss (kg) & 0.131 & 0.146 & 0.172 & 0.088 & 0.088 & 0.125 & 0.17 & 0.208 & 0.215 \\
\hline 5 & Total weight of organic materials $(\mathrm{kg})$ & 0.2847 & 0.2304 & 0.1996 & 0.2712 & 0.22351 & 0.1865 & 0.2965 & 0.23476 & 0.22131 \\
\hline
\end{tabular}

Table 9. Orthogonal array used

\begin{tabular}{|r|r|r|r|r|r|}
\hline S/N & A & B & C & D & E \\
\hline 1 & 1 & 1 & 1 & 1 & 1 \\
\hline 2 & 1 & 1 & 1 & 1 & 2 \\
\hline 3 & 1 & 1 & 1 & 1 & 3 \\
\hline 4 & 1 & 2 & 2 & 2 & 1 \\
\hline 5 & 1 & 2 & 2 & 2 & 2 \\
\hline 6 & 1 & 2 & 2 & 2 & 3 \\
\hline 7 & 1 & 3 & 3 & 3 & 1 \\
\hline 8 & 1 & 3 & 3 & 3 & 2 \\
\hline 9 & 1 & 3 & 3 & 3 & 3 \\
\hline 10 & 2 & 1 & 2 & 3 & 1 \\
\hline 11 & 2 & 1 & 2 & 3 & 2 \\
\hline 12 & 2 & 1 & 2 & 3 & 3 \\
\hline 13 & 2 & 2 & 3 & 1 & 1 \\
\hline 14 & 2 & 2 & 3 & 1 & 2 \\
\hline 15 & 2 & 2 & 3 & 1 & 3 \\
\hline 16 & 2 & 3 & 1 & 2 & 1 \\
\hline 17 & 2 & 3 & 1 & 2 & 2 \\
\hline 18 & 2 & 3 & 1 & 2 & 3 \\
\hline 19 & 3 & 1 & 3 & 2 & 1 \\
\hline 20 & 3 & 1 & 3 & 2 & 2 \\
\hline 21 & 3 & 1 & 3 & 2 & 3 \\
\hline 22 & 3 & 2 & 1 & 3 & 1 \\
\hline 23 & 3 & 2 & 1 & 3 & 2 \\
\hline 24 & 3 & 2 & 1 & 3 & 3 \\
\hline 25 & 3 & 3 & 2 & 1 & 1 \\
\hline 26 & 3 & 3 & 2 & 1 & 2 \\
\hline 27 & 3 & 3 & 2 & 1 & 3 \\
\hline
\end{tabular}


Table 10.. Taguchi-Pareto $\mathrm{L}_{27} 3^{5}$ experimental design for A356 alloy cast for application 1

\begin{tabular}{|c|c|c|c|c|c|c|c|c|c|c|c|c|c|c|c|c|c|c|}
\hline $\mathrm{S} / \mathrm{N}$ & A & $\mathrm{B}$ & $\mathrm{C}$ & $\mathrm{D}$ & $\mathrm{E}$ & S/N Ratio & A & B & $\mathrm{C}$ & $\mathrm{D}$ & $E$ & S/N Ratio & A & B & $\mathrm{C}$ & $\mathrm{D}$ & $\mathrm{E}$ & S/N Ratio \\
\hline 1 & 1.898 & 4271.1 & 1.77 & 0.131 & 0.2847 & -67.839583875 & 1.808 & 3774.5 & 1.72 & 0.088 & 0.2712 & $\begin{array}{l}-66.765977970 \\
\end{array}$ & 1.975 & 4658.0 & 1.84 & 0.17 & 0.2965 & -68.592778619 \\
\hline 2 & 1.898 & 271.1 & 1.77 & 0.131 & 2304 & -67.839583868 & 1.808 & 774.5 & 1.72 & 088 & 0.22351 & -66.765977963 & 1.975 & 4658.0 & 1.84 & 0.17 & 0.2348 & -68.592778612 \\
\hline 3 & 1.898 & 4271.1 & 1.77 & 0.131 & 0.1996 & -67.839583865 & 1.808 & 3774.5 & 1.72 & 0.088 & 0.1865 & -66.765977958 & 1.975 & 4658.0 & 1.84 & 0.17 & 0.2213 & -68.592778611 \\
\hline 4 & 1.898 & 5379.9 & 1.68 & 0.146 & 0.2847 & -69.844272496 & 1.808 & 3452.2 & 1.58 & 0.088 & 0.2712 & -65.990708548 & 1.975 & 7512.6 & 1.74 & 0.208 & 0.2965 & -72.744593315 \\
\hline 5 & 1.898 & 379.9 & 1.68 & 0.146 & .2304 & -69.844272492 & 1.808 & 3452.2 & 1.58 & 0.088 & 0.22351 & -65.990708539 & 1.975 & 7512.6 & 1.74 & 0.208 & 0.2348 & -72.744593312 \\
\hline 6 & 1.898 & 379.9 & 1.68 & 0.146 & .1996 & -69.844272490 & 1.808 & 3452.2 & 1.58 & 0.088 & 0.1865 & -65.990708534 & 1.975 & 7512.6 & 1.74 & 0.208 & 0.2213 & -72.744593312 \\
\hline 7 & 1.898 & 4545.1 & 1.83 & 0.172 & 0.2847 & -68.379657795 & 1.808 & 3283.4 & 1.70 & 0.125 & 0.2712 & -65.555265847 & 1.975 & 5803.0 & 2.04 & 0.215 & 0.2965 & -70.501839921 \\
\hline 8 & 1.898 & 4545.1 & 1.83 & 0.172 & 0.2304 & -68.379657789 & 1.808 & 3283.4 & 1.70 & 0.125 & 0.22351 & -65.555265837 & 1.975 & 5803.0 & 2.04 & 0.215 & 0.2348 & -70.501839917 \\
\hline 9 & 1.898 & 45.1 & 1.83 & 0.172 & 1996 & 557787 & 1.8 & 3283.4 & 1.70 & 25 & 65 & 831 & 1.975 & 803.0 & 2.04 & .215 & 0.2213 & 9916 \\
\hline 10 & 1.826 & 4271.1 & 1.68 & 0.172 & 2847 & -67.839583740 & 1.788 & 3774.5 & 1.58 & 125 & 12 & 810 & 1.863 & 4658.0 & 1.74 & .215 & 0.2965 & 8464 \\
\hline 11 & 1.826 & 4271.1 & 1.68 & 0.172 & 0.2304 & -67.839583734 & 1.788 & 3774.5 & 1.58 & 0.125 & 0.22351 & 65977802 & 1.863 & 4658.0 & 1.74 & .215 & 0.2348 & -68.592778458 \\
\hline 12 & 1.826 & 4271.1 & 1.68 & 0.172 & 0.1996 & -67.839583730 & 1.788 & 3774.5 & 1.58 & & & 65977798 & 1.863 & 4658.0 & 1.74 & 0.215 & 0.2213 & -68.592778457 \\
\hline 13 & 1.826 & 5379.9 & 1.83 & 0.131 & .2847 & -69 & 1.7 & 34 & 1.70 & 0.088 & 712 & 665 & 1. & 2.6 & 2.04 & 0.17 & 0.2965 & 3368 \\
\hline 14 & 1.826 & 5379.9 & 1.83 & 0.131 & 0.2304 & -69.844272530 & 1.788 & 3452.2 & 1.70 & 0.088 & 0.22351 & 990708656 & 1.863 & 7512.6 & 2.04 & 0.17 & 0.2348 & -72.744593365 \\
\hline 15 & 1.826 & 5379.9 & 1.83 & 0.131 & 0.1996 & -69.844272528 & 1.788 & 3452.2 & 1.70 & 0.088 & 0.1865 & -65.990708651 & 1.863 & 7512.6 & 2.04 & 0.17 & 0.2213 & -72.744593365 \\
\hline 16 & 1.826 & 4545.1 & 1.77 & 0.146 & .2847 & & & & 1.72 & & & & & & & 0.208 & & 39765 \\
\hline 17 & 1.826 & 45.1 & .77 & 146 & .2304 & -68 & 1.7 & 3283.4 & 1.72 & 0.088 & 0.22351 & 333 & 1.863 & 5803.0 & 1.84 & 0.208 & 0.2348 & 9761 \\
\hline 18 & 1.826 & 4545.1 & 1.77 & 0.146 & 1996 & -68.379657683 & 1.788 & 3283.4 & 1.72 & 0.088 & 0.1865 & -65.555265827 & 1.863 & 5803.0 & 1.84 & 0.208 & 0.2213 & -70.501839760 \\
\hline 19 & 1.998 & 4271.1 & 1.83 & 0.146 & 0.2847 & -67.839584020 & 1.865 & 3774.5 & 1.70 & 0.088 & 0.2712 & -66.765978013 & 2.215 & 4658.0 & 2.04 & 0.208 & 0.2965 & -68.592778978 \\
\hline 20 & 1.998 & 271.1 & 183 & 0.146 & & & & & 1.70 & 0088 & 0.22351 & & & & 2.04 & 0.208 & 0.2348 & 2778972 \\
\hline 21 & 1.998 & 271.1 & 1.83 & 46 & 96 & 10 & 1.8 & 3774.5 & 1.70 & 88 & 65 & 01 & 2.215 & 4658.0 & 2.04 & 0.208 & 0.2213 & 78970 \\
\hline 22 & 1.998 & 5379.9 & 1.77 & 0.172 & 0.2847 & -69.844272603 & 1.865 & 3452.2 & 1.72 & 0.125 & 0.2712 & -65.990708795 & 2.215 & 7512.6 & 1.84 & 0.215 & 0.2965 & -72.744593420 \\
\hline 23 & 1.998 & 5379.9 & 1.77 & 0.172 & 0.2304 & -69.844272598 & 1.865 & 3452.2 & 1.72 & 0.125 & 0.22351 & -65.990708787 & 2.215 & 7512.6 & 1.84 & 0.215 & 0.2348 & -72.744593417 \\
\hline 24 & 1.998 & 379.9 & 1.77 & 0.172 & 0.1996 & & 1.865 & 3452.2 & 1.72 & & & & 2.215 & 7512.6 & 1.84 & 0.215 & 0.2213 & -72.744593417 \\
\hline 25 & 1.998 & & 1.6 & & & & & & 1.2 & & & & & & 1.74 & 0.17 & 0.2965 & -70.501839902 \\
\hline 26 & 1.998 & 4545.1 & 1.68 & 0.131 & 0.2304 & -68.379657758 & 1.865 & 3283.4 & 1.58 & 0.088 & 0.22351 & -65.555265760 & 2.215 & 5803.0 & 1.74 & 0.17 & 0.2348 & -70.501839898 \\
\hline 27 & 1.998 & 4545.1 & 1.68 & 0.131 & 0.1996 & -68.379657755 & 1.865 & 3283.4 & 1.58 & 0.088 & 0.1865 & -65.555265754 & 2.215 & 5803.0 & 1.74 & 0.17 & 0.2213 & -70.501839897 \\
\hline
\end{tabular}

e-ISSN: 2289-7771 
Table 11 shows the revised $\mathrm{S} / \mathrm{N}$ ratios response table for application 1 . It creates an optimal parametric setting of $A_{2} B_{1} C_{2} D_{3} E_{2}$ and Table 11 creates an optimal parametric setting of $A_{2} B_{3} C_{2} D_{1} E_{2}$ and $A_{2} B_{1} C_{2} D_{3} E_{2}$, respectively.

Table 11. Revised Taguchi-Pareto S/N ratio response for A356 alloy (Scenario 1 to 3)

\begin{tabular}{|c|c|c|c|c|c|c|}
\hline \multirow{6}{*}{ Scenario 1} & Level & A & B & $\mathrm{C}$ & $\mathrm{D}$ & $\mathrm{E}$ \\
\hline & 1 & -68.68783805 & -67.83958387 & -68.68783805 & -68.68783805 & -68.68783806 \\
\hline & 2 & -68.68783798 & -69.84427254 & -68.687838 & -68.68783806 & -68.68783805 \\
\hline & 3 & -68.68783812 & -68.37965775 & -68.68783811 & -68.68783804 & -68.68783805 \\
\hline & delta & $1.39858 \mathrm{E}-07$ & 2.004688668 & $1.16467 \mathrm{E}-07$ & 2.33742E-08 & $8.22016 \mathrm{E}-09$ \\
\hline & Rank & 2 & 1 & 3 & 4 & 5 \\
\hline \multirow{7}{*}{ Scenario 2} & Level & A & B & $\mathrm{C}$ & $\mathrm{D}$ & $\mathrm{E}$ \\
\hline & 1 & -66.10398411 & -66.76597792 & -66.1039842 & -66.10398413 & -66.10398414 \\
\hline & 2 & -66.1039841 & -65.99070866 & -66.10398403 & -66.10398413 & -66.10398413 \\
\hline & 3 & -66.10398419 & -65.55526581 & -66.10398417 & -66.10398414 & -66.10398413 \\
\hline & delta & 8.69411E-08 & 1.210712113 & $1.60227 \mathrm{E}-07$ & $1.62638 \mathrm{E}-08$ & $1.3854 \mathrm{E}-08$ \\
\hline & Rank & 2 & 1 & 3 & 5 & 4 \\
\hline & Level & $\mathrm{A}$ & B & $\mathrm{C}$ & $\mathrm{D}$ & $\mathrm{E}$ \\
\hline \multirow{5}{*}{ Scenario 3} & 1 & -70.61307061 & -68.59277868 & -70.6130706 & -70.61307063 & -70.61307064 \\
\hline & 2 & -70.61307053 & -72.74459337 & -70.61307056 & -70.61307068 & -70.61307063 \\
\hline & 3 & -70.61307076 & -70.50183986 & -70.61307075 & -70.6130706 & -70.61307063 \\
\hline & delta & $2.343 \mathrm{E}-07$ & 4.151814683 & $1.95197 \mathrm{E}-07$ & $8.42219 \mathrm{E}-08$ & $5.27012 \mathrm{E}-09$ \\
\hline & Rank & 2 & 1 & 3 & 4 & 5 \\
\hline
\end{tabular}

The outcomes of Taguchi-Pareto analysis relate with the analysis of variance table that shows the density of cast 1 , the weight of cast 1 , weight of cast 2 , total weight of organic material and weight loss parameters were significant to A356 alloy cast.

Taguchi ABC Analysis

The factor levels were grouped into factor $\mathrm{A}, \mathrm{B}$ and $\mathrm{C}$ using the $\mathrm{ABC}$ classification. Table 12 describes a special mix-design $L_{24}$ orthogonal array for experimental design. This formed an ideal parameter setting based on the individual influence of the factor levels regardless of their initial factor grouping. Table 13 shows a revised Taguchi-ABC S/N response 
Table 12. Taguchi-ABC $L_{24}$ experimental design for A356 alloy cast for scenarios 1,2 and 3

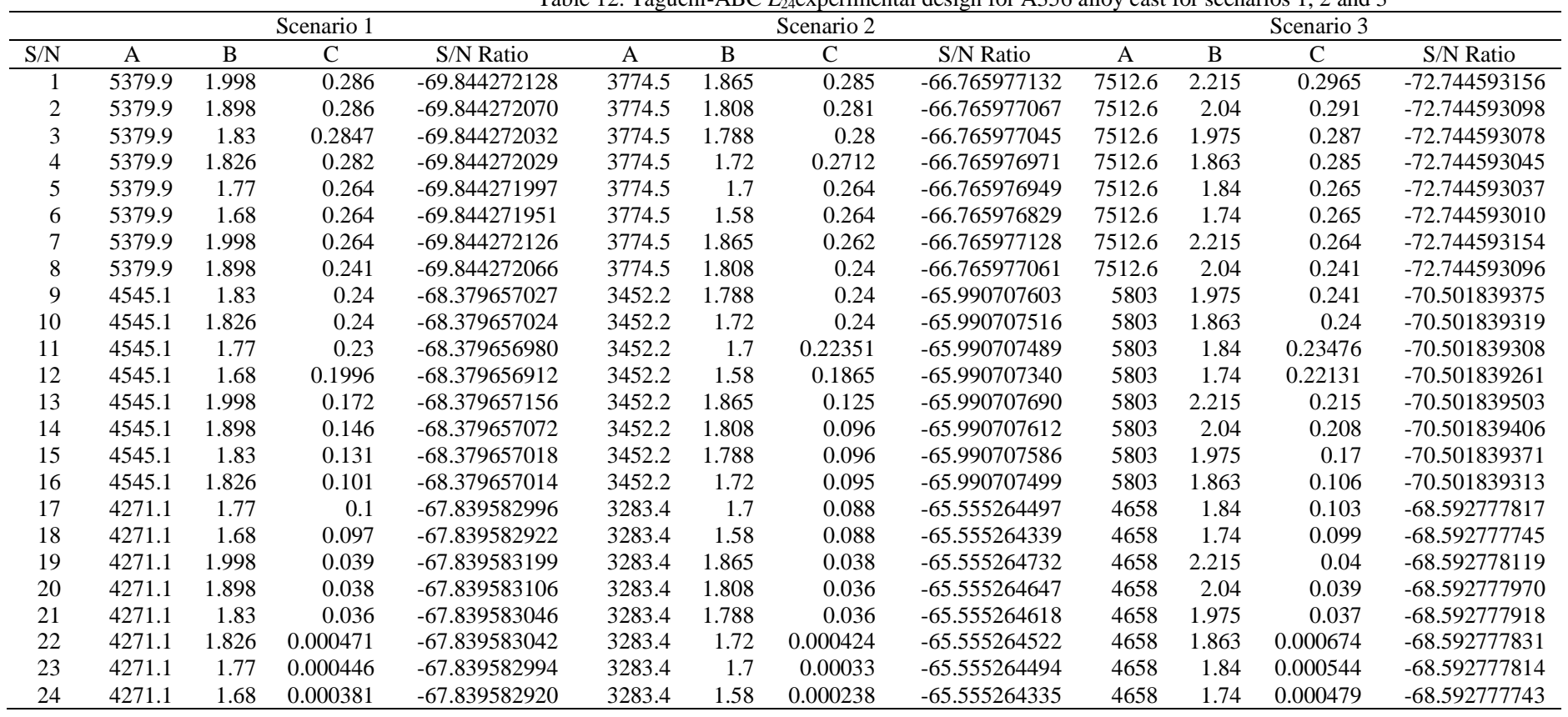

e-ISSN: 2289-7771 
Table 13. Revised Taguchi-ABC S/N ratio response for A356 alloy for scenarios 1, 2 and 3

\begin{tabular}{|c|c|c|c|c|c|c|c|c|c|}
\hline & \multicolumn{3}{|c|}{ Scenario 1} & \multicolumn{3}{|c|}{ Scenario 2} & \multicolumn{3}{|c|}{ Scenario 3} \\
\hline S/N & A & B & $\mathrm{C}$ & A & $\mathrm{B}$ & $\mathrm{C}$ & A & B & $\mathrm{C}$ \\
\hline 1 & -69.84427205 & -68.97694615 & -69.84427213 & -66.76597702 & -66.26948167 & -66.76597713 & -72.74459308 & -71.14595098 & -72.74459316 \\
\hline 2 & -68.37965703 & -68.97694608 & -69.84427207 & -65.99070754 & -66.2694816 & -66.76597707 & -70.50183936 & -71.14595089 & -72.7445931 \\
\hline 3 & -67.83958303 & -68.61079228 & -69.84427203 & -65.55526452 & -66.07566421 & -66.76597705 & -68.59277787 & -70.58526244 & -72.74459308 \\
\hline delta & 2.004689022 & -68.61079228 & -69.84427203 & 1.2107125 & -66.07566413 & -66.76597697 & 4.151815215 & -70.58526238 & -72.74459304 \\
\hline \multirow[t]{22}{*}{ Position } & 2 & -68.47577374 & -69.844272 & 2 & -65.96680336 & -66.76597695 & 2 & -70.10799699 & -72.74459304 \\
\hline & & -68.47577368 & -69.84427195 & & -65.96680321 & -66.76597683 & & -70.10799694 & -72.74459301 \\
\hline & delta & 0.501172476 & -69.84427213 & delta & 0.30267846 & -66.76597713 & delta & 1.037954043 & -72.74459315 \\
\hline & Position & 3 & -69.84427207 & Position & 3 & -66.76597706 & Position & 3 & -72.7445931 \\
\hline & & & -68.37965703 & & & -65.9907076 & & & -70.50183937 \\
\hline & & & -68.37965702 & & & -65.99070752 & & & -70.50183932 \\
\hline & & & -68.37965698 & & & -65.99070749 & & & -70.50183931 \\
\hline & & & -68.37965691 & & & -65.99070734 & & & -70.50183926 \\
\hline & & & -68.37965716 & & & -65.99070769 & & & -70.5018395 \\
\hline & & & -68.37965707 & & & -65.99070761 & & & -70.50183941 \\
\hline & & & -68.37965702 & & & -65.99070759 & & & -70.50183937 \\
\hline & & & -68.37965701 & & & -65.9907075 & & & -70.50183931 \\
\hline & & & -67.839583 & & & -65.5552645 & & & -68.59277782 \\
\hline & & & -67.83958292 & & & -65.55526434 & & & -68.59277774 \\
\hline & & & -67.8395832 & & & -65.55526473 & & & -68.59277812 \\
\hline & & & -67.83958311 & & & -65.55526465 & & & -68.59277797 \\
\hline & & & -67.83958305 & & & -65.55526462 & & & -68.59277792 \\
\hline & & & -67.83958304 & & & -65.55526452 & & & -68.59277783 \\
\hline & & & -67.83958299 & & & -65.55526449 & & & -68.59277781 \\
\hline & & & -67.83958292 & & & -65.55526434 & & & -68.59277774 \\
\hline & & Delta & 2.004689208 & & delta & 1.210712797 & & delta & 4.151815267 \\
\hline & & Position & 1 & & position & 1 & & position & 1 \\
\hline
\end{tabular}


In the Taguchi-ABC analysis, Table 13 shows that $A_{3} B_{6} C_{2,4}$ is the optimal parameter setting for A356 alloy. The Taguchi-ABC analysis shows that when these factors are merged can give what is needed in the A356 alloy cast as a cause of their influence.

\section{Limitation of the Study}

A limitation of the study is the exclusion of the temperature parameter with the geometric features of the two-phase casing process. Conventionally, and as developed in this work, only the common geometrical parameters are considered. Though temperature may be argued to be out of scope of geometric parameters yet in the case of the two-phase casting considered temperature may be significant as it may open up a novel viewpoint into the build-up of a joint geometric and heat parametric model for casting design and development decisions for lowering the variance related to the dimensional problem of the cast. In improving on this weakness, future research may refer to the classic work of Kumar et al. [28] in which the temperature parameter is stated as a strong point in the casting analysis. Besides, the simulation used to address the problem will enhance this study if adopted. Nonetheless, our research differs from that of Kumar et al. [28] in that the two-phases of canoe-shaped and cuboid-shaped melting processes were not considered. Also, organic materials were used in the current work, which is absent in that work.

\section{Significance of research findings}

This study suggests a matchless prospect to provide evidence on an earlier unreported aspect of A356 alloy reinforced with organic materials. It logically explains how the cast geometries in terms of volume of the cast, length, weight, density, height, width, and breadth that influence the responses in casting A356 alloy could be optimised for locally sourced A356 out-of-use engines in a developing country's domain. It reports an innovative pair of optimisation methods, TaguchiPareto and Taguchi-ABC, which were newly launched as novel tools for concurrent optimisation and prioritisation of factors of the casting process. The optimisation of the parameters in a twophase casting process of the A356 alloy composite comprising the canoe-shaped and cuboidshaped outputs will improve practices and theory of casting and process optimisation and can assist to examine the interactions among the casting parameters and thus influence the choice of important factors with which scarce resources could be channelled for casting process operational efficiency.

Thus, the idea of prioritisation of important factors in an optimisation engagement demonstrates a shift in optimisation engagements from the traditional factor-level determination, coupled with orthogonal arrays and optimal parametric settings for the choice of the most relevant factors in the computational system. An examination of the prioritisation of factors in the optimisation scheme will enable the casting engineer to take cost and geometric decisions at the design and cast product development phases and significantly enhance cast geometry decision making. The interpretations of prioritisation are valuable to establish restraint on the less important factors that may not warrant the commitment of scarce casting resources in the engineering set-up. Also, the research reveals the potential for geometric optimisation of casting parameters utilising the standard parameters of the casting product dimensions. Furthermore, the research introduced a novel blend of organic materials to enhance the environmentally conscious production of cast products.

e-ISSN: 2289-7771 


\section{Conclusion}

This section offers the answer to the principal research question of process parametric optimisation while considering the accuracy of measurements in a melting and solidification process involving two stages of casting. The first stage entails the development of a mould that is canoe-shaped in which the waste automobile engine blocks are melted and poured into a sand mould that was developed based on a canoe-shaped pattern. This process only involves melting and no organic reinforcements are added. In the second stage of melting and solidification, the same process as for stage one was repeated with variations in the mould type as well as the addition of the organic reinforcements. The conclusion section takes into account all the findings as well as the discussions previously elaborated on. The central focus was to determine the optimal values of process parameters in light of the prioritisation of factors. In the first scenario of the problem, from the eleven factors of concern given the density of cast 1 the first position while the second and third positions were offered to the weight of cast 1 and weight of cast 2, respectively. For the second scenario, the first to third positions were awarded to the density of cast 1 , weight of cast 2 and weight of cast 1 , respectively. The worst position for this scenario was however awarded to the volume of cast 1 . For the third scenario, factors representing the density of casts 1 , the weight of cast 1 and the weight of cast 2 were given the first, second and third positions, respectively. The work factor was given to weight loss. Generally, the highest position is given to the density of cast 1 in all the three scenarios while weights of casts 1 and 2 competed interchangeably for positions two and three in the three scenarios. Thus, we conclude that the density and weights of the cats play a significant role in influencing the final accuracy of measurements and the parameters of choice for optimisation.

To our knowledge, this study is the foremost study to systematically exploit the procedure to optimise the process parameters of the melting and solidification processes of A356 reinforced with organic materials in an attempt to attain accuracy in measurement. The outcome of the study offers a good understanding of the significance of such an investigation. Nonetheless, a lot needs to be accomplished to completely gain insight the waste-to-wealth conversion process of out-ofuse engine blocks of automobiles reinforced with organic materials. Certainly, many additional research opportunities in this groundbreaking area are opened for investigation. Some of these studies are suggested here:

- A study on factor analysis may supplement data and show the way to the enhanced systematic substantiation of the strong influencing factors that manufacturing resources could be concentrated on given the limited availability of these sources. This activity will assist in planning for manufacturing in terms of design and implementation.

- The study may use response surface methodology as an optimisation tool to possibly generate innovative insights. Is there a correlation in the results of Taguchi methods and response surface methodology?

- Another alternative is to carry out a rather comparable investigation using clustering techniques

- The integration of techniques and concepts such as response surface methodology and Pareto, $\mathrm{ABC}$ analysis and multi-criteria methods as an additional extremely germane aspect for the supplementary examination.

- By tradition, a vast number of composite manufacturing systems are worked on in optimisation while the ranking of parameters is intuitively carried out to operate in a

e-ISSN: 2289-7771 
component manner given the fact that the anticipated operating conditions of the composite manufacturing plant do not deviate. This assertion may not be correct as the manufacturing business is not limited to the controllable conditions but also uncontrollable circumstances. The later is overwhelming and substantially influences both the inputs and outputs to the system. Thus, the composite manufacturing environment could substantially be uncertain before the manufacturing process is carried out. Given that circumstances, it is essential that a mechanism is developed, which autonomously triggers learning from an artificial intelligence tool and fuzzy logic system. The information on the A356 alloy composite parameters may be gathered over time and used while the learning continues to enhance the optimisation performance of the Taguchi methodical modelled system. Thus, a strong area of improvement for this work in the future is the integration of artificial neural networks and fuzzy logic. A starting point may be the fusion of fuzzy logic and the Taguchi method. A simplistic approach involving the independent study of any of these methods may also be interesting in future studies. Finally, it should be asserted that if priority is not given to optimisation of the A356 alloy composite the condition of the environment in which the fabrication is carried out could transform drastically in a matter of time. The model developed from these proposed methods ought to respond to such changes from the perspective of an online situation

\section{References}

[1] Vega L. Y., López L., Valdés C.F., Chejne F. 2019, Assessment of energy potential of wood industry wastes through thermochemical conversions, Waste Management, Vol. 87, 108-118

[2] Rejeski D., Zhao F., Huang Y. 2018, Research needs and recommendations on environmental implications of additive manufacturing, Additive Manufacturing, Vol. 19, 21-28

[3] Stone J., Garcia-Garcia G., Rahimifard S. 2019, Development of a pragmatic framework to help food and drink manufacturers select the most sustainable food waste valorisation strategy, Journal of Environmental Management, Vol. 247, 425-438

[4] Ingrao C., Faccilongo N., Gioia L.D., Messineo A. 2018, Food waste recovery into energy in a circular economy perspective: A comprehensive review of aspects related to plant operation and environmental assessment, Journal of Cleaner Production, Vol. 184, 869-892

[5] Dhingra R., Das S. 2014, Life cycle energy and environmental evaluation of downsized vs. lightweight material automotive engines, Journal of Cleaner Production, Vol. 85, 347-358

[6] Kang S-H, Han J-J, Hwang W-T, Lee S-M, Kim H-K 2019, Failure analysis of die casting pins for an aluminum engine block, Engineering Failure Analysis, Vol. 104, 690703

[7] Timelli G., Caliari D., Rakhmonov J. 2016, Influence of process parameters and Sr addition on the microstructure and casting defects of LPDC A356 alloy for engine blocks, Journal of Materials Science \& Technology, Vol. 32, No. 6, 515-523

[8] Lombardi A., Ravindran C., MacKay R. 2015, Optimization of the solution heat

e-ISSN: 2289-7771 
treatment process to improve mechanical properties of $319 \mathrm{Al}$ alloy engine blocks using the billet casting method, Materials Science and Engineering: A, Vol. 633, 125-135

[9] Sun J., Le Q., Fu L., Bai J., Huo H. 2019, Gas entrainment behavior of aluminum alloy engine crankcases during the low-pressure-die-casting process, Journal of Materials Processing Technology, Vol. 266, 274-282

[10] Aigbodion and Ezema I.C., 2019, Multifunctional A356 alloy/PKSA ${ }_{n p}$ composites: Microstructure and mechanical properties, Defence Technology, DOI: 101016/j.dt.2019.05.017

[11] Kumar T.S., Shakini S., Kumar K.K., Thavamani R., Subramanian R., 2018, Bagasse ash reinforced A356 alloy composite: Synthesis and characterisation, Materials Today: Proceedings, Vol. 5, 7123-7130

[12] Ochieze B.O., Nwobi-Okoye C.C., Atanwo P.N., 2018, Experimental study of the effect of wear parameters on the wear behaviour of A356 alloy/cow horn particulate composites, Defence Technology, Vol. 14, 77-82

[13] Nwobi-Okoye C.C., Ochieze B.Q., Okiy S., 2019, Multi-objective optimisation and modelling of age hardening process using ANN, ANFIS and genetic algorithm: Results from aluminium alloy A356/cow horn particulate composite, Journal of Materials Research and Technology, Vol. 8, No. 3, 3054-3075

[14] Ozturk I., Agaoghu GH., Ezri E., Dispinar D., Orhan G., 2018, Effects of strontium addition on the microstructure and corrosion behaviour of A356 aluminium alloy, Journal of Alloys and Compounds, Vol. 763, 384-391

[15] Lin J-H., Zhao H-D., Huang J-M., 2019, Spatial interfacial heat transfer and surface characteristics during gravity casting of A356 alloy, Transactions of Nonferrous Metals Society of China, Vol. 29, 43-50

[16] Yang C-L., Li Y-B., Dang B., Lu H-B., Liu F., 2015, Effects of cooling rate on solution heat treatment of as-cast A356 alloy, Transactions of Nonferrous Metals Society of China, Vol. 25, 3189-3196

[17] Elahi M.A., and Shabestari S.G., 2016, effects of various melt and heat treatment conditions on impact toughness of A356 aluminium alloy, Transactions of Nonferrous Metals Society of China, Vol. 26, 956-965

[18] Carneiro V.H., Puga H., Meireles J., 2018, Heat treatment as a route to trial or the yielddamping properties in A356 alloys, Materials Science and Engineering A, Vol. 729, 1-8

[19] Haskel T., Verran G.O., Barberi R., 2018, Rotating and bending fatigue behaviour of A356 aluminium alloy: Effects of strontium addition and T6 heat treatment, International Journal of Fatigue, Vol. 114, 1-10

[20] Di-Giovanni M.T., Mortsell E.A., Saito T., Akhtar S., Di-Sabatino M., Li Y, Cerri E, 2019, Influence of $\mathrm{Cu}$ addition on the heat treatment response of A356 foundry alloys, Materials Today Communications, Vol. 19, 342-348

[21] Wu D-Y., Kang J., Feng Z-H., Su R., Liu C-H., Li T., Wang L-S., 2019, Utilising a novel modifier to realize multi-refinement and optimised heat treatment of A356 alloy, Journal of Alloys and Compounds, Vol. 791, 628-640

[22] Ajibade O.A., Agunsoye J.O., Oke S.A. 2019b, Optimisation of water absorption parameters of dual-filler filled composites using Taguchi and moderated Taguchi techniques, Kufa Journal of Engineering, Vol. 10, No. 2, 134-151

[23] Wei Z., Lei Y., Yan H., Xu X., He J., 2019 Microstructure and mechanical properties of

e-ISSN: 2289-7771 
A356 alloy with yttrium addition processed by hot extrusion, Journal of Rare Earths, Vol. 37, 659-667

[24] Jalilvand M.M., Mazaheri Y., Heidarpour A., Roknian M. 2019, Development of $\mathrm{A} 356 / \mathrm{Al}_{2} \mathrm{O}_{3}+\mathrm{SiO}_{2}$ surface hybrid nanocomposite by friction stir processing, Surface and Coatings Technology, Vol. 360, 121-132

[25] Nayak R.K., Venugopal S., 2018, Prediction of shrinkage allowance for tool design of aluminium alloy (A356) investment casting, Materials Today: Proceedings, Vol. 5, No. 11, 24997-25005

[26] Cui X. L., Wu Y. Y., Gao T., Liu X. F. 2014, Preparation of a novel Al-3B-5Sr master alloy and its modification and refinement performance on A356 alloy, Journal of Alloys and Compounds, Vol. 615, pp. 906-911

[27] Ma G., Li. R., Li R. 2016, Effect of $\mathrm{Mg}_{2} \mathrm{Si}$ particles on low-temperature behaviour of A356 alloy, Materials Science and Engineering A, Vol. 674, 666-671.

[28] Kumar S. D. Karthik D., Mandal A., Kumar J.S.R.P., 2017, Optimisation of thixo forging process parameters or A356 alloy using Taguchi experimental design and deform simulation, Materials Today: Proceedings, Vol. 4., 9987-9991

[29] Long H.C., Chen J.H., Liu C.H., Li C.H., Li Y.Y., 2013, The negative effect of solution treatment on age hardening of A356 alloy, Material Science and Engineering A., Vol. $566,112-118$

[30] Vencl, A., Bobic, I. and Stojanovic, B. 2014, Tribological properties of A356 Al-Si alloy composites under dry sliding conditions, Industrial Lubrication and Tribology, Vol. 66 No. 1, 66-74

[31] Staia M. H., Sanchez C., Cruz M. R., Roman A., Lesage J., Mesmacque G. \& Dahotre N. B. 2002, Tungsten laser alloying of A356 Al alloy - tribological performance and characterisation, Surface Engineering, Vol. 18, No. 4, 270-276

[32] Kumar S.D., Vundavilli P.R., Mandal A., Mantry S. \& Chakraborty M. 2016, Erosion response of thixoformed $\mathrm{A}_{356}-5 \mathrm{TiB}_{2}$ in-situ composite using Taguchi's experimental design, Tribology Transactions, Vol. 60, No. 1, 39-46

[33] Hashemi S. H. \& Ashrafi A. 2017, Characterisations of low phosphorus electroless Ni and composite electroless Ni-P-SiC coatings on A356 aluminium alloy, Transactions of the IMF: The International Journal of Surface Engineering and Coatings, Vol. 96, No. 1, 52-56

[34] Ajibade O.A., Agunsoye J.O., Oke S.A., 2015, Metal removal process optimisation using Taguchi-simplex method with case study applications, Cankaya University Journal of Science and Engineering, Vol. 12, No. 2, 33-58

[35] Ajibade O.A., Agunsoye J.O., Oke S.A., 2016, Tapped density optimisation for four agricultural wastes: Part I - Taguchi technique and mean response determination, Acta Periodica Technologica, Vol. 47, 109-127

[36] Ajibade O.A., Agunsoye J.O., Oke S.A. 2019a. Poisson distribution: How tensile properties of particulate polymer composites are enhanced in a Poisson-motivated Taguchi method, Engineering and Applied Science Research, Vol. 46, No. 2, 130-141. 